\title{
Optimal design of binary cycle power plants for water-dominated, medium- temperature geothermal fields
}

\author{
Alessandro Franco*, Marco Villani \\ Dipartimento di Energetica "L. Poggi", \\ Università di Pisa, \\ Largo Lucio Lazzarino - 56126 Pisa, Italy
}

\begin{abstract}
Exploitation of lower temperature, water-dominated geothermal fields is analyzed, and a methodology for optimizing geothermal binary plants is discussed. The geothermal fluid inlet temperatures considered are in the $110-160{ }^{\circ} \mathrm{C}$ range, while the return temperature of the brine is assumed to be between 70 and $100{ }^{\circ} \mathrm{C}$. The analysis shows that the brine specific consumption, ranging from 20 to $120 \mathrm{~kg} / \mathrm{s}$ for each net MW produced, and the efficiency of the plants, ranging from 20 to $45 \%$ in terms of Second Law efficiency, are dictated mainly by the combination of the brine inlet temperature, the brine rejection temperature and the energy conversion cycle being used. For given operating conditions and with correct matching between working fluid and energy conversion cycle, it is possible to obtain very similar performances in a number of different cases. It is shown that optimization of the plant can yield improvements of up to $30-40 \%$ in terms of reduction of brine specific consumption compared to conventional design.
\end{abstract}

Keywords: Geothermal; Thermodynamics; Medium-temperature geothermal resources; Binary plants; Exergy analysis; Rejection temperature; Optimum design.

\footnotetext{
${ }^{*}$ Corresponding author. Tel.: +39 050 2217154; Fax: +39 0502217150. E-mail address: alessandro.franco@ing.unipi.it (A. Franco).
} 


\section{Nomenclature}

d diameter of the tubes of recovery heat exchanger (m)

e $\quad$ specific exergy $\left(\mathrm{J} \mathrm{kg}^{-1}\right)$

Ex exergy flow (W)

h enthalpy $\left(\mathrm{J} \mathrm{kg}^{-1}\right)$

I exergy loss flow (W)

$\mathrm{L} \quad$ length of the tubes of recovery heat exchanger (m)

$\mathrm{m} \quad$ mass flow rate $\left(\mathrm{kg} \mathrm{s}^{-1}\right)$

$\mathrm{n} \quad$ number of cooling system units (fans)

$\mathrm{p}$ pressure (bar)

Q heat flow rate (W)

$\mathrm{S}$ heat transfer surface $\left(\mathrm{m}^{2}\right)$

$\mathrm{S} \quad$ (specific) entropy $\left(\mathrm{J} \mathrm{kg}^{-1} \mathrm{~K}^{-1}\right)$

$\mathrm{T}$ temperature $\left({ }^{\circ} \mathrm{C}\right)$

$\mathrm{T}_{\mathrm{o}} \quad$ reference temperature $(\mathrm{K})$

$\mathrm{T}^{*} \quad$ average temperature $(\mathrm{K})$

$\mathrm{U}$ heat transfer coefficient $\left(\mathrm{W} \mathrm{m}^{-2} \mathrm{~K}^{-1}\right)$

$\mathrm{V} \quad$ specific volume $\left(\mathrm{m}^{3} \mathrm{~kg}^{-1}\right)$

$\mathrm{X} \quad$ steam quality

W power (W)

Greek symbols

$\beta \quad$ specific brine consumption $\left(\mathrm{kg} \mathrm{MJ} \mathrm{MJ}^{-1}\right)$

$\Delta \mathrm{T} \quad$ temperature difference $\left({ }^{\circ} \mathrm{C}\right)$

$\Delta \mathrm{p} \quad$ pressure drop (bar)

$\eta \quad$ efficiency

$\eta_{\mathrm{I}} \quad$ First Law efficiency

$\eta_{\text {II }} \quad$ Second Law efficiency

Subscripts and abbreviations

cond condenser, condensation

cr critical value 
CS cooling system

DPLSH Dual Pressure Level with Superheater

fans fans

geo geothermal fluid

gross gross power

HRC heat recovery cycle

i i-th level

in inlet

is isentropic

max maximum

net net power

o reference state

PL pressure levels

pp pinch point

pump circulation pump

RAN Rankine Cycle

RANSH Rankine Cycle with superheater

RHE recovery heat exchanger

rej rejection

sat saturation

sat1 saturation at first (low) pressure level

sat2 saturation at second (high) pressure level

SH superheater

ST steam turbine

w-fluid working fluid

1-8 thermodynamic states related to the working fluid in Fig. 7 (a) and (b) 


\section{Introduction}

Among geothermal energy resources, the medium- and low-temperature water-dominated systems, with temperatures between 110 and $160^{\circ} \mathrm{C}$, are the most abundant (Hochstein, 1990; Barbier, 2002). Binary power plants (or Organic Rankine Cycle units; ORC) are the best energy conversion systems to exploit them, both from a technical and environmental point of view.

In a binary cycle power plant the heat of the geothermal water is transferred to a secondary working fluid, usually an organic fluid that has a low boiling point and high vapor pressure when compared to water at a given temperature. The cooled geothermal water is then returned to the ground to recharge the reservoir (DiPippo, 2008). Such a geothermal plant has no emissions to the atmosphere except for water vapor from the cooling towers (only in case of wet cooling) and any losses of working fluid. Thus, environmental problems that may be associated with the exploitation of higher temperature geothermal resources, like the release of greenhouse gases (e.g. $\mathrm{CO}_{2}$ and $\mathrm{CH}_{4}$ ) and the discharge of toxic elements (e.g. $\mathrm{Hg}$ and $\mathrm{As}$ ), are avoided. Another advantage of the binary technology is that the geothermal fluids (or brines) do not contact the moving mechanical components of the plant (e.g. the turbine), assuring a longer life for the equipment. Binary plants have allowed the exploitation of a large number of fields that may have been very difficult (or uneconomic) using other energy conversion technologies, thereby increasing significantly the development of geothermal resources worldwide (Table 1) (Schochet, 1997; DiPippo, 2004).

There exist a great number of studies addressing both the different characteristics of geothermal fields and the various types of power plants that could be used in their exploitation for electricity production; Barbier (2002), Bertani (2005), Lund (2007) and DiPippo (2008) provide analyses of the various technological solutions and of the state of the art. The design of binary plants, although widely addressed in the literature (e.g. Gnutek and BryszewskaMazurk, 2001; Kanoglu, 2002; Di Pippo, 2004; Hettiarachchi et al., 2007; Kaplan, 2007; Kose, 2007; Moya and DiPippo, 2007) is still an area of active research. At present this technology is not at a stage of development capable of providing "standard machinery", and each installation is designed for the conditions at a given location. Every system is tailored to specific geothermal fluid characteristics: the big manufacturers in this field, like Ormat, Mafi Trench, Siemens and UTC Power have adopted this approach. 
For low-temperature geothermal systems that only produce hot water, geothermal binary power plants show very low values of First Law efficiencies (5-10\%); even Second Law efficiencies are typically in the 25 to $45 \%$ range (Kanoglu, 2002; Kose, 2007; Moya and DiPippo, 2007). In recent years many studies have been done in attempts to increase binary plant efficiencies; they focused mainly on the combination of the working fluid and the heat recovery cycle.

Among others, Di Pippo (2004) proposed both a heat recovery exchanger with a cascade of evaporators and the use of a multicomponent working fluid (e.g. a Kalina cycle), while Kanoglu (2002) discussed a recovery cycle with both a high- and a low-pressure turbine. Gnutek and Bryszewska-Mazurk (2001) proposed a power plant with more than two pressure levels, and Gu and Sato (2001) studied the use of supercritical cycles.

The large variation in geothermal brine temperatures, pressures and chemical compositions makes very difficult the choice of working fluid and heat recovery cycle, and the sizing of heat transfer devices.

One of the problems of geothermal binary plants, often neglected in the literature, is the rejection of heat at low temperature (thermal pollution). If no adequate water source is available, a dry cooling system must be used. Although such a system solves the problem of water supply, it raises many others. The parasitic power consumption is relatively high because of the need for forced ventilation; a dry cooling system can absorb from $10-12 \%$ of gross power (under ideal conditions), to as much as $40-50 \%$ if the ambient temperature is very close to the condensation temperature. The capital cost is also quite high; $30-35 \%$ of the total capital cost of the geothermal project.

The relatively high cost of binary plants may have limited the number of installations worldwide. Moreover, experience has shown that even if mass production of components can lead to lower manufacturing costs, the economics of scale works against these small plants. Gawlik and Kutscher (2000) present a fairly detailed analysis of the costs of small-scale geothermal plant, with output powers below $1 \mathrm{MW}$. Total plant capital cost ranges from $€$ 2000 to 4000 per installed kW (as evidenced by the analysis given in Table 1a and 1b of Gawlik and Kutscher, 2000) and can be also higher when exploration and drilling costs are considered.

A geothermal binary power plant is characterized by high brine specific consumption and low plant efficiencies, and by the requirement for large heat transfer surfaces both for the heat 
recovery heat exchanger and for the condensation system. There can also be wide differences between a conventionally designed and an optimal power plant. Consequently, successful implementation of a geothermal binary plant is necessarily related to the development of optimum design strategies both from the point of view of energy production and cost.

There have been a number of attempts to define criteria and guidelines for the optimal design of binary cycle power plants (Gnutek and Bryszewska-Mazurek, 2001; Borsukiewicz-Gozdur and Nowak, 2007; Hettiarachchi et al., 2007); these analyses, however, do not give a complete solution of the problem. First of all, the influence of brine rejection temperature is not correctly analyzed, because the authors do not perform sensitivity analyses with respect to changes in rejection temperature. This temperature is selected based mainly on the chemical composition of the geothermal fluid; in particular, it is necessary that the rejection temperature should be high enough to avoid silica oversaturation, which could lead to silica scaling and serious fouling problems in recovery heat exchangers, and in mineral deposition in pipes and valves (Grassiani, 2000). Considering that low-enthalpy geothermal fields have temperatures between 110 and $160{ }^{\circ} \mathrm{C}$ and that it is difficult to use rejection temperatures lower than $70-80^{\circ} \mathrm{C}$, the latter temperature is a crucial parameter in plant design. Moreover, the influence of cooling system performance on the thermodynamic efficiency of the plant is often neglected.

A binary cycle power plant is composed of three closely interrelated subsystems, the heat recovery cycle (HRC), the recovery heat exchanger (RHE) and the cooling system (CS). Actually, the RHE is part of the HRC, but making a distinction between them allows considering a separate sequence of the thermal and fluid dynamic problems.

Here the optimal design of such a plant is studied from a more general perspective, paying attention not only to the problem of matching the heat recovery and thermodynamic cycle (temperature of the geothermal source, rejection temperature, working fluid and thermodynamic cycle), but also to determine the effects of the RHE (pressure drop and pumping power) and of the CS (power subtracted in connection with the selected condensation temperature) on the performance of the plant. 


\section{Low-temperature geothermal technology overview}

Currently, the total installed power worldwide of geothermal binary power plants is about 700 MWe, representing about $8 \%$ of the geothermal power installed worldwide (Table 2). In a geothermal binary power plant the enthalpy of the geofluid is transferred via a heat exchanger to a secondary working fluid that has a low boiling point relative to water at the same pressure. The working fluid passes through a recovery cycle, usually a Rankine or Rankine cycle with superheat, to produce electrical power.

Binary plants can be classified into two types: plants with a wet cooling system, where the working fluid is condensed by cooling water, and plants with a dry cooling system, where the heat is rejected directly to the air (Fig. 1). In the latter case, which will be analyzed below, no water supply is necessary, but a large heat transfer surface is required and the fans of the cooling system do consume a significant fraction of the gross generated power.

The heat recovery cycle can be a basic or superheated Rankine cycle or a more complex recovery cycle (e.g. a dual-pressure level Rankine cycle or a supercritical cycle). At present, there exist few power plants with dual pressure levels (12.4 MWe at Stillwater, California, USA, and $40 \mathrm{MWe}$ at Heber, California, USA) and there are no operating plants that use a supercritical recovery cycle. This is mainly due to the small size of such power plants and to the low economic returns.

The selection of the working fluid is based on thermodynamic considerations; i.e. on the thermo-physical properties of the geothermal and working fluids, as well as the heat recovery cycle chosen. The working fluids include hydrocarbons (mainly butane and pentane) and synthetic refrigerants (mainly HFCs). Multicomponent working media, where evaporation and condensation occur at variable temperatures, as for example in the Kalina cycle, could increase the thermodynamic efficiency and should be considered (Angelino and Colonna Di Paliano, 1998).

The geothermal binary power plants currently in operation can be divided according to different classifications: the first and more meaningful is surely the dichotomy between "stand-alone" or "bottoming cycles". Another classification is based on the installed power so that it is possible to identify two main groups according to the total power produced. The first group includes medium and large binary power plants (with output power of at least $5 \mathrm{MW}$ ), and bottoming units of geothermal combined power plants (the direct flash cycle constitutes the "topping cycle"), with installed capacities of up to $100 \mathrm{MWe}$. The power rating for the 
bottoming cycles is given in Table 3. These plants usually use basic Rankine cycles and dry cooling towers. More detailed information about the various plants can be found in the open literature (e.g. Angelino et al., 1995; Bertani, 2005, 2007, 2008; Kaplan; 2007).

Brine specific consumption in geothermal binary plants is often higher than $50 \mathrm{~kg} / \mathrm{s}$ per MW produced. The parasitic power loss is very large by comparison with other types of power plants (combustion or dry or flash steam power plants). Circulation pumps and cooling tower fans consume a considerable fraction of the generated power. The electricity required to run the circulation pumps is relatively constant and is generally between 2 and $10 \%$ of the gross plant output, being a function of both the working fluid and the operating pressure. The power usage by the cooling tower fans is strongly affected by operating and environmental conditions, and can vary between 10 and more than $30 \%$ of the gross power.

The second type of geothermal binary plant is the small "stand alone" power systems (with output power below $5 \mathrm{MW}$ according to the definition given by Lund and Boyd, 1999), pilot experimental plants or small binary units installed in fields where previously a flash-steam plant had been used to generate power using less than $150^{\circ} \mathrm{C}$ fluids (DiPippo, 1999; Schochet, 2000); the installed capacities range from some hundreds of $\mathrm{kW}$ to a few MW. These plants often operate through advanced thermodynamic cycles (dual pressure level Rankine cycle or Kalina cycle) and may also use different or unconventional working fluids, such as ammoniawater mixtures (e.g. Husavik, Iceland). The characteristics of this second group of plants are given in Table 4. They cover a wide range of geothermal fluid temperatures $\left(74-145^{\circ} \mathrm{C}\right)$ so that brine specific consumption, which is strongly dependent on the thermodynamic and chemical properties of the geofluid, lies in the range from 15 to $69 \mathrm{~kg} / \mathrm{s}$ for each MW of electricity produced. Note that the first value, corresponding to Otake (Japan), should not be compared with others in Table 4 since that particular plant uses a steam-hot water mixture, not just hot water as in the others (DiPippo, 2004).

From the analyses reported in the literature, it is difficult to identify general criteria for the optimum design of geothermal binary plants. The large number of parameters and variables involved in the design process require a specific analytical methodology, identifying variables, objective functions and constraints, and an optimization strategy (sequential, multilevel, etc.) (Rao, 1996). 


\section{Model, variables and merit parameters of a binary cycle power plant}

As noted above, the design of a geothermal binary plant needs to take into account the particular type of thermodynamic cycle, the pump and turbine, the recovery heat exchanger and condenser, and the cooling system. For this reason, the process has to consider a large number of design variables and operating parameters.

The temperature, pressure and chemical composition of the geothermal fluid, the rejection temperature, the ambient temperature and the maximum rate of energy extraction that can be sustained without a significant decrease of the water temperature in the reservoir, can be considered as fundamental variables of the problem. Some of them cannot be modified (geothermal fluid inlet temperature) and others lie in well-defined ranges (rejection temperature, geothermal fluid flow rate, ambient temperature). All of these variables are relevant for defining the technical specifications of the plant (thermodynamic cycle, saturation pressure, maximum temperature), but some are more important than others.

The exergy potential of a geothermal resource depends strongly on the geothermal fluid and rejection temperatures. The fluid inlet temperature is a parameter controlled primarily by the characteristics of the geothermal field, even if changing well depths can sometimes modify it. On the other hand, the rejection temperature is set so to avoid scaling problem (see Introduction), and is one of the most important factors limiting the complete utilization of geothermal resources (Stefansson, 1997; Mroczek et al., 2000). Based on the analyses presented in the literature, it seems difficult to lower the rejection temperature below $70^{\circ} \mathrm{C}$. Considering that low-enthalpy geothermal fields have temperatures in the $110-160^{\circ} \mathrm{C}$ range, too high rejection temperatures can make the exploitation of such a system unprofitable.

To determine the exergetic availability of a geothermal resource, two ratios can be defined:

$$
\begin{aligned}
& \frac{E x}{E x_{0}}=\frac{\left(T_{\text {geo }}-T_{\text {rej }}\right)-T_{\mathrm{o}} \ln \left(\mathrm{T}_{\text {geo }} / \mathrm{T}_{\text {rej }}\right)}{\left(\mathrm{T}_{\text {geo }}-\mathrm{T}_{\mathrm{o}}\right)-\mathrm{T}_{\mathrm{o}} \ln \left(\mathrm{T}_{\text {geo }} / \mathrm{T}_{\mathrm{o}}\right)} \\
& \frac{\mathrm{Ex}}{\mathrm{Q}_{\mathrm{o}}}=\frac{\left(\mathrm{T}_{\text {geo }}-\mathrm{T}_{\text {rej }}\right)-\mathrm{T}_{\mathrm{o}} \ln \left(\mathrm{T}_{\text {geo }} / \mathrm{T}_{\text {rej }}\right)}{\left(\mathrm{T}_{\text {geo }}-\mathrm{T}_{\mathrm{o}}\right)}
\end{aligned}
$$

Both ratios assume that the geothermal brine has a constant specific heat. 
Eq. (1) represents the ratio of (a) the theoretical work that can be extracted from the geofluid for given inlet geofluid temperatures and assumed rejection temperatures, and (b) the maximum theoretical work that can be extracted for given inlet geofluid and dead-state temperatures. It provides an upper limit to the Second Law efficiency. Fig. 2(a) shows the dependence of the $\mathrm{Ex} / \mathrm{Ex}_{\mathrm{o}}$ ratio on the temperature of the source $\left(\mathrm{T}_{\mathrm{geo}}\right)$ and the rejection temperature of the brine $\left(\mathrm{T}_{\text {rej }}\right)$.

Eq. (2) represents the ratio of (a) the theoretical work that can be extracted from the geofluid for given inlet geofluid temperatures and assumed rejection temperatures and (c) the maximum theoretical heat that can be extracted for given inlet geofluid temperatures and dead-state temperatures. Fig. 2(b) gives an estimation of the upper limit of the First Law efficiency. The data are based on a reference value $\left(\mathrm{T}_{\mathrm{o}}\right)$ of $298 \mathrm{~K}\left(25^{\circ} \mathrm{C}\right)$, that represents a theoretical lower limit value for rejection temperature.

The average and the range of variation of the ambient temperature are also important, especially when dry cooling towers are used to condense the working fluid; in this case the condensation temperature greatly affects parasitic power consumption. If the condensation and ambient temperatures are too close, the increase of power consumption in the cooling system severely reduces the net power production. A compromise is necessary between the intrinsic thermal efficiency of the recovery cycle and the power loss due to parasitic consumption.

The variation of ambient temperature presents a difficult problem because it changes not only annually and seasonally, but also hourly; the condensation temperature cannot follow such a trend. The difference between ambient and condensation temperatures can vary by a factor of three or four between its maximum and minimum values; i.e. during winter nights and summer days, respectively.

Identification of the characteristics of the geothermal fluids and of the environment is the starting point of the binary plant design, and influences the specification of variables such as the choice of working fluid (cryogenic, synthetic refrigerant, multicomponent medium), the recovery cycle (Rankine, Rankine with superheater, dual pressure level Rankine, supercritical, Kalina), the condensing temperature, the recovery heat exchanger and its thermal and fluiddynamic design, and the cooling system.

The selection of suitable fluids for use in binary cycle plant is quite a complex problem and cannot be dissociated from the choice of the heat recovery cycle (Liu et al., 2004). The 
saturation curve is one of the key parameters for matching the working fluid and the recovery cycle. There are two types of vapor saturation curves in the temperature-entropy (T-s) diagram: fluids with positive slopes (dT/ds) like R134a and R152a and fluids with negative slopes like Isobutane and n-Pentane (Fig. 3). In the first case, since the vapor expands through the turbine along a sub-vertical line on the T-s diagram, saturated vapor at the turbine inlet remains superheated (dry) throughout the turbine, and it is not necessary to resort to a Rankine cycle with superheat.

On the other hand, for a working fluid of the wet type (e.g. Isobutane and n-Pentane), a superheater is necessary in order to complete the expansion in the superheated vapor zone, or to avoid excess moisture at the turbine exhaust. In recent years, multicomponent working media, composed of two or more fluids evaporating and condensing at variable temperatures, have also been considered. Potentially they achieve a better match between the working and geothermal fluids, and the working fluid and the cooling medium; in particular they tend to reduce the exergy loss due to heat transfer.

The available thermodynamic cycles can be divided into five main groups:

- Recovery cycles with one pressure level (Rankine; Rankine with superheater)

- Recovery cycles with two pressure levels

- Supercritical recovery cycles

- Recovery cycles with non-isothermal evaporation and condensation (e.g. Kalina)

- Recuperative (regenerative) cycles

The choice of the working fluid and heat recovery cycle is done on the basis of thermodynamic performance, economic considerations (capital cost of the plant) and adaptability to variations in operating conditions. This last parameter is important because the temperature of a geothermal fluid may decrease after the start of field exploitation.

For performance analyses of binary power plants, First and Second Law efficiencies are usually used. However, the first one (Eq. 3) does not reflect the thermodynamic quality of the conversion process, even though it can be used to compute the heat discharge to the environment. The Second Law efficiency is more appropriate for assessing the performance of binary plants. Second Law efficiency (Eq. 4) may be defined using a conventional reference temperature $T_{0}$. 


$$
\begin{aligned}
& \eta_{\mathrm{I}}=\frac{\mathrm{W}_{\text {net }}}{\mathrm{m}_{\mathrm{geo}}\left(\mathrm{h}_{\mathrm{geo}}-\mathrm{h}_{\mathrm{rej}}\right)} \\
& \eta_{\mathrm{II}}=\frac{\mathrm{W}_{\text {net }}}{\mathrm{m}_{\mathrm{geo}} \cdot \mathrm{e}_{\mathrm{geo}}}=\frac{\mathrm{W}_{\mathrm{net}}}{\mathrm{m}_{\mathrm{geo}}\left[\left(\mathrm{h}_{\mathrm{geo}}-\mathrm{h}_{\mathrm{o}}\right)-\mathrm{T}_{\mathrm{o}} \cdot\left(\mathrm{s}_{\mathrm{geo}}-\mathrm{s}_{\mathrm{o}}\right)\right]}
\end{aligned}
$$

where $h_{o}$ and $s_{o}$ are the reference values for enthalpy and entropy (calculated for $T=T_{o}$ ). Eq. (4) is the standard expression for Second Law efficiency.

Since, the First and Second Law efficiencies are also linked to the brine inlet temperature, it is possible to compare the various available combinations of the source, rejection and condensation temperatures, and obtain an indication about the specific power of the plant. For this reason another important merit parameter that can be considered in the analysis is the mass flow rate to generate a fixed power output, or specific brine consumption, which is given by:

$$
\beta=\frac{\mathrm{m}_{\text {geo }}}{\mathrm{W}_{\text {net }}}
$$

The parameter $\beta$ is often considered when the minimization of geothermal fluid flow rate (specific consumption) for a given power is suggested as an objective function for optimal design (Hettiarachchi et al., 2007).

\section{A methodology for the optimal design of binary cycle power plants}

The optimal design of a binary geothermal power plant can be considered as a multiobjective, multivariable constrained optimization problem. Three main temperatures can be considered as constraints, i.e. the geothermal fluid, rejection, and ambient temperatures. Finding the optimum solution is a complex task, because the problem embraces various fields with many variables of different types (i.e. thermodynamic, geometric and thermo-fluid-dynamic variables), together with the combination of the three subsystems (see below) that can be considered from different points of view and are linked to the recovery cycle, to the sizing of equipment (size of heat exchanger), pinch point, pressure drops and to the management of the geothermal field/power plant system. (The pinch point is the place in the heat exchanger where the geothermal brine and the working fluid experience the minimum temperature 
difference. The value of this difference is known as the pinch-point temperature difference; DiPippo, 2008, page 162-163).

The strategy proposed here decomposes the binary cycle into three subsystems (HRC, RHE and CS) and organizes it at two hierarchical levels with objectives sequentially defined [system level (thermodynamic cycle) and component level (RHE and condenser)], but with iteration from lower to upper levels. The whole optimization problem can be reformulated into manageable size sub-problems. The results from the higher optimization level (recovery and thermodynamic cycle) represent the input data for the detailed design of the RHE and CS. The effects of the optimum component design (pressure losses, pumping power) are iterated at the system level (Fig. 4).

At the first level, the thermodynamic variables (matching between working fluid and recovery cycle, saturation pressure, maximum temperature, condensing temperature) are taken into account, while at the second level, using the first-step results as input data and considering the two heat transfer models (one describing the RHE and one the CS), the sizing and the optimization of the two heat transfer devices can be carried out. The results of the component level optimization can affect the results of the first-level optimization (in particular the design of the dry cooling system). For this reason the RHE, even though it is part of the Thermodynamic cycle since it is needed to operate the cycle, is shown downstream of that cycle (Fig. 4).

A schematic of the optimization strategy, also showing the variables involved, is given in Figs 5-6. The effect of the RHE and CS design are taken into account in terms of pumping power requirements: concerning the RHE they are related to the pumping power needed to increase the pressure from the condenser pressure to the inlet pressure for the RHE. A detailed description of the optimum design of components is given in Franco and Villani (2008a).

The optimization procedure can be summarized as follows: for given fluid, heat recovery cycle configuration and turbine isentropic efficiency and a tentative value of the cooling temperature, the parameters of the heat recovery cycle (working fluid mass flow rate, operating pressure and maximum temperature) are defined in order to minimize the mass flow rate needed for a specified turbine expansion power (e.g. $1 \mathrm{MW}$ ). Then, the parasitic losses related to the pumping power and operating the CS are estimated, and the specific brine consumption $(\beta)$ is calculated (Fig. 5). 
Referring to Fig. 6, the HRC design involves matching the working fluid recovery cycle with the minimization of the parameter $\beta$. The RHE thermal and fluid-dynamic model of heat transfer allows one to define the dimensions of the various sections of the heat exchanger (preheater, evaporator, superheaters), as well as the pressure drops in the geothermal and working fluids. The temperatures and the mass flow rates for both fluids, defined at the first level, are needed as input variables. The model is constructed for a shell-and-tube heat exchanger, using three main geometric variables (number, diameter and length of the tubes). Pinch-point temperature differences have been selected in the $7-10{ }^{\circ} \mathrm{C}$ range.

For the two standard recovery cycles represented in Fig. 7 (Rankine cycle and dual pressure level with superheater), if the use of the approximation $v \Delta P$ for the enthalpy rise across the pump is accepted, the net output power of the plant can be defined as,

$$
\begin{aligned}
& \mathrm{W}_{\text {netRAN }}=\mathrm{W}_{\text {gross }}-\mathrm{W}_{\text {pump }}-\mathrm{W}_{\mathrm{cs}}=\mathrm{m}_{\mathrm{w}-\text { fluid }}\left[\left(\mathrm{h}_{3}-\mathrm{h}_{4}\right)-\frac{\mathrm{v}_{\mathrm{w}-\text { fluid }}\left(\mathrm{p}_{\text {sat }}-\mathrm{p}_{\text {cond }}\right)}{\eta_{\text {pump }}}\right]-\mathrm{W}_{\mathrm{CS}} \\
& \mathrm{W}_{\text {net,DPLSH }}=\mathrm{W}_{\text {gross }}-\mathrm{W}_{\text {pump }}-\mathrm{W}_{\mathrm{cs}} \\
& =\mathrm{m}_{2}\left(\mathrm{~h}_{5}-\mathrm{h}_{7}\right)+\mathrm{m}_{1}\left(\mathrm{~h}_{6}-\mathrm{h}_{7}\right)-\frac{\left(\mathrm{m}_{1}+\mathrm{m}_{2}\right) \mathrm{v}_{\text {pcond }}\left(\mathrm{p}_{\text {sat } 1}-\mathrm{p}_{\text {cond }}\right)}{\eta_{\text {pump }}}-\frac{\mathrm{m}_{2} \mathrm{v}_{\text {psat } 1}\left(\mathrm{p}_{\text {sat } 2}-\mathrm{p}_{\text {sat } 1}\right)}{\eta_{\text {pump }}}-\mathrm{W}_{\mathrm{CS}}
\end{aligned}
$$

The parameters used for the comparative analysis are,

$$
\begin{aligned}
& \beta_{\mathrm{RAN}}=\frac{\mathrm{m}_{\text {geo }}}{\mathrm{W}_{\text {net, RAN }}} \\
& \beta_{\text {DPLSH }}=\frac{\mathrm{m}_{\text {geo }}}{\mathrm{W}_{\text {net, DPLSH }}}
\end{aligned}
$$

For Second Law efficiency, a simplified expression derived from Eq. (4), in which $\mathrm{h}_{0}$ and $\mathrm{s}_{0}$ assume null values, is considered. The total exergy loss flow of the plant is, 
$\mathrm{I}=\mathrm{I}_{\mathrm{ST}}+\mathrm{I}_{\mathrm{RHE}}+\mathrm{I}_{\text {cond }}+\mathrm{I}_{\text {rej }}=\mathrm{m}_{\text {geo }} \cdot \mathrm{e}_{\text {geo }}-\mathrm{W}_{\text {net }}$

For the recovery cycle represented in Fig. 7(a), one has

$$
\begin{aligned}
& \mathrm{I}_{\text {rej }}=\mathrm{m}_{\text {geo }} \cdot \mathrm{e}_{\text {rej }} \\
& \mathrm{I}_{\text {cond }}=\mathrm{m}_{\mathrm{w}-\text { fluid }} \cdot\left[\mathrm{e}_{4}-\mathrm{e}_{1}\right] \approx \mathrm{m}_{\mathrm{w}-\text { fluid }} \mid \Delta \mathrm{h}_{\text {cond }} \cdot\left(1-\mathrm{T}_{\mathrm{o}} / \mathrm{T}_{\text {cond }}^{*}\right) \\
& \mathrm{I}_{\mathrm{ST}}=\mathrm{m}_{\mathrm{w}-\text { fluid }} \cdot\left[\mathrm{e}_{3}-\mathrm{e}_{4}\right]-\mathrm{W}_{\text {gross }} \\
& \mathrm{I}_{\mathrm{RHE}}=\mathrm{m}_{\text {geo }} \cdot\left(\mathrm{e}_{\text {geo }}-\mathrm{e}_{\text {rej }}\right)-\mathrm{m}_{\mathrm{w}-\text { fluid }} \cdot\left(\mathrm{e}_{4}-\mathrm{e}_{1}\right)
\end{aligned}
$$

The power required to run the cooling system $\left(\mathrm{W}_{\mathrm{CS}}\right)$ is computed by considering it as a modular system composed by a number of standard optimized units in which large fans force air (in cross flow) through several rows of finned tubes. In this case, the input variables are the condensation temperature, the working fluid mass flow rate and the average value of the ambient temperature; the operating variables are the number and configuration of the modules and the velocity of the air. The model permits calculation of the total heat transfer surface that is required (i.e. the number of modular units) and the power consumed to operate the fans. Reducing the temperature difference between the condenser and the environment would require the addition of extra units and result in larger power consumption that must be considered in relation to the increase in gross power from the recovery cycle. A computer program was written to carry out this multiobjective, multivariable constrained optimization. 


\section{Performance evaluations of binary plant configurations and sensitivity analysis}

Here we present some performance results obtained using the model described in the previous section; a wide range of operating conditions were covered. In particular, we considered 110$160{ }^{\circ} \mathrm{C}$ geothermal fluids, $70-100{ }^{\circ} \mathrm{C}$ brine rejection temperatures, and $30-40{ }^{\circ} \mathrm{C}$ condensing temperatures. In all the cases analyzed, common reference values of ambient temperature $\left(\mathrm{T}_{0}\right.$ $=298 \mathrm{~K})$ and of geothermal fluid pressure $\left(\mathrm{p}_{\mathrm{geo}}=15 \mathrm{bar}\right)$ were assumed.

While the values selected for the inlet temperature are common, the following analyses consider the cases in which the rejection temperature is as low as $70{ }^{\circ} \mathrm{C}$, although this requires geothermal sources with very low concentrations of $\mathrm{SiO}_{2}, \mathrm{Al}$ and Fe. (Gallup, 1998).

The use of various available fluids and different thermodynamic recovery cycles is discussed next. For convenience, the analysis is made for a net power output of $1 \mathrm{MW}$. The working fluids were selected in relation to their critical temperature and chemical nature; about 30 different organic fluids were tested (Villani, 2008). In order to give a representative review of the organic working fluids that can be used in a geothermal binary power plant, two hydrocarbons (Isobutane, n-Pentane), two synthetic refrigerants (R134a, R152a) and two mixtures (R401A, R407C) were considered (Table 5). The selected fluids cover a wide range of critical temperatures, i.e. between $86.7^{\circ} \mathrm{C}(\mathrm{R} 407 \mathrm{C})$ and $196.6^{\circ} \mathrm{C}(\mathrm{n}$-Pentane).

To obtain the power output, the isentropic efficiencies of the turbine and circulation pump have been assumed to be 0.85 . The analyzed recovery cycles include both basic and superheat Rankine cycles, and advanced cycles (dual pressure Rankine cycles and supercritical cycle). The recuperative cycle is only briefly considered here for the reason that - although it appears a very promising solution for binary cycle power plants - it is very sensitive to changes in environmental conditions here represented by a variation of the condensation temperature; this would require a site-specific study. Analyses were performed to evaluate:

_ performance limits of basic configurations under the various operating conditions;

- influence of the fluids with reference to standard thermodynamic cycles;

- performance improvements due to advanced recovery cycles (dual pressure and supercritical cycles);

- distribution of the various exergy losses as a function of operating conditions and of the recovery cycle used. 
Although the brine specific consumption $(\beta)$ is used as general performance indicator, the First and Second Law efficiencies are also considered according to the definitions given by Eqs. (3) and (4). Fig. 8 provides an exhaustive view of the potential and the limits of a geothermal binary plant operating in the range of temperatures cited above, covering different combinations of inlet and rejection temperatures and a fixed condensation temperature $\left(\mathrm{T}_{\text {cond }}\right.$ $=40^{\circ} \mathrm{C}$ ). All the cases discussed assume a basic plant configuration (a low-pressure Rankine or Rankine cycle with superheat) with optimized parameters (saturation pressure, maximum working fluid temperature). It can be seen from Fig. 8 that the best results overall are obtained with the classical hydrocarbons, although in some cases a refrigerant is to be preferred (in particular R152a when the difference between source and rejection temperatures is high). The use of mixtures seems to be less advantageous.

It is clear that there are large differences between the various operating conditions. A $30^{\circ} \mathrm{C}$ decrease in geothermal brine temperature increases the specific consumption by a factor of 2 to 3, and there is a difference of about $500 \%$ between the best and worst conditions. In some cases $\left[\left(\mathrm{T}_{\text {geo }}-\mathrm{T}_{\mathrm{rej}}\right)=110-80^{\circ} \mathrm{C}\right.$ and $\left.130-100^{\circ} \mathrm{C}\right]$ the exploitation of geothermal field appears not to be feasible due to a combination of thermodynamic and economic considerations. Moreover the geothermal fluid inlet temperature seems to be more relevant to improving the power plant performance than is the rejection temperature. Considering the Case 1 (Table 6) as a reference, a reduction of inlet temperature by $30{ }^{\circ} \mathrm{C}$ (Case 2; Table 6) requires that the geothermal fluid brine flow rate be doubled to obtain the same net power. A combined reduction of inlet temperature and increase of rejection temperature by $10^{\circ} \mathrm{C}\left(\right.$ i.e. $\mathrm{T}_{\text {geo }}=150^{\circ} \mathrm{C} ; \mathrm{T}_{\text {rej }}=80^{\circ} \mathrm{C}$ ) entails a relatively modest increase in geothermal fluid flow rate.

Table 6 shows for all the six selected working fluids the effects of optimization if advanced recovery cycles (i.e. a dual-pressure Rankine cycle and a supercritical cycle) are used. For a given combination of temperatures $\left(T_{\text {geo }}\right.$ and $\left.T_{\text {rej }}\right)$ the difference between a basic configuration and an optimized one can be significant: the reduction of brine specific consumption can be as much as $30 \%$, with an efficiency increase of up to $40 \%$ (comparison between the worst and the best results obtained in each of the three cases in Table 6).

As far as the thermodynamic cycles are concerned, for working fluids with low critical temperatures (synthetic refrigerants and mixtures), a supercritical solution may be considered, while for those with high critical temperatures (Isobutane and n-Pentane) a 
dual-pressure solution is to be preferred. In some cases, in particular for low geothermal fluid inlet temperatures $\left(130^{\circ} \mathrm{C}\right)$, the use of advanced solutions, like the supercritical cycle, does not seem to improve plant performance; see the analysis of the second case in Table 6.

Fig. 9 shows the effects of condensation temperature on power plant performance: for larger differences between source and rejection temperatures, the best results are obtained with R152a. On the other hand, hydrocarbons perform better for smaller temperature differences.

Analysis of the computed data also illustrates some further effects of condensation temperature. In particular it may be noted that a reduction in this temperature results in two different and opposite effects. That is, an improvement in gross thermodynamic efficiency of the recovery cycle, but an increase in cooling system power consumption. For the two cases analyzed $\left(\mathrm{T}_{\text {geo }}=130{ }^{\circ} \mathrm{C}, \mathrm{T}_{\text {rej }}=100^{\circ} \mathrm{C}\right.$, and $\left.\mathrm{T}_{\text {geo }}=160^{\circ} \mathrm{C}, \mathrm{T}_{\text {rej }}=70{ }^{\circ} \mathrm{C}\right)$, it appears that the reduction of condensation temperature from 40 to $30{ }^{\circ} \mathrm{C}$ does not produce a substantial increase in the net efficiency of the power plant with the exception of some cases. This occurs because the thermodynamic improvement (a larger enthalpy drop) is balanced by an increase in cooling system pumping power requirements. However, while the reduction of brine specific consumption and the increase in efficiency are negligible but positive, the increase in needed heat exchange surfaces, not considered here, can be significant (Franco and Villani, 2008a), and therefore it can lead to a rise in power plant costs.

An exergy analysis of the various optimized plant configurations for some representative cases is given in Fig. 10 showing the proportions of the exergy losses in the various system components. In particular it appears that the RHE, the condenser, and rejection at a high temperature are all causes of relatively high exergy losses $(8-25 \%, 7-28 \%$ and $11-$ $34 \%$, respectively). Moreover, it is possible to observe the effect of reduced losses in the condenser and the increased exergy losses due to the operation of the fans, which change the condensation temperature (compare the cases 160-70-40 and 160-70-30, where the three values correspond to $T_{\text {geo }}, T_{\text {rej }}$ and $T_{\text {cond }}$, respectively; Fig. 10).

A comparison of the 160-100-40 and 130-70-40 cases shows that an exergy analysis alone is not sufficient to optimize plant design; the productivity of geothermal wells must also be taken into account. The 130-70-30 case appears to give a better result in terms of the 
percentage of the incoming exergy that is converted into net work, however it is important to recognize that to obtain the same output power about $30 \%$ more geothermal fluid must be used than in the 160-100-40 case because the actual incoming exergy is far less than in the second case. The results shown in Fig. 10 together with the data concerning brine specific consumption given in Table 6 and Figs. 8 and 9 give a comprehensive view of the situation. The implementation of supercritical configurations was also analyzed. Improvements associated with the use of such cycles have been discussed widely in the literature. (e.g. Gu and Sato, 2001) The benefits of these configurations emerge also from the present analysis (see Table 6). In some cases, they can improve binary plant performance by about $5-6 \%$ in terms of Second Law efficiency. The use of supercritical cycles is appropriate if the geothermal fluid temperature is quite high (above $140-150^{\circ} \mathrm{C}$ ), but only with particular working fluids. In general supercritical cycles do not offer any advantage, as is also shown in Table 6, because the efficiency increase of the heat recovery system is negated by an increase of the parasitic energy requirements and a reduction in the enthalpy drop.

Fig. 11 shows the effects on exergy analysis of a thermodynamic optimization of the recovery cycle using three different working fluids. For each fluid, a basic recovery cycle (Rankine or Rankine with superheat) and an advanced cycle (Dual-pressure-level Rankine, regenerative Rankine or supercritical) are compared. For some working fluids the regenerative and supercritical solutions (first and second case) can reduce exergy losses due both to the RHE and CS. But operating at relatively high pressure (70-90 bar) causes a considerable increase (200-300\% higher) of power loss due to the working fluid circulation pumps. In addition, the presence of supercritical conditions in parts of the system introduces further technical (higher internal pressure and higher internal power usage, which further exacerbate components difficulties) and economic problems that Sones and Krieger (2000) discussed with reference to the Heber binary power plant.

The analyses presented here give a general overview of the performance of a binary power plant using a particular geothermal fluid, but the essential problem is to identify some values both for brine specific consumption and for First and Second Law efficiencies that make it profitable to exploit a given geothermal resource. The performance of such a plant can be analyzed with a thermo-economic criterion, in which both the thermodynamics of the binary cycle and the costs of the plant are taken into account simultaneously. This concept, described in detail in Franco and Villani (2008b), could allow limiting values to be established for (upper) brine specific consumption and for (lower) efficiencies. For example, the exploitation 
of a geothermal field with a relatively low brine temperature $\left(100-130{ }^{\circ} \mathrm{C}\right)$, that involves high brine specific consumption (about $100 \mathrm{~kg} / \mathrm{s}$ per MW) and low values of First and Second Law efficiencies ( $6 \%$ and $20 \%$, respectively) is unlikely to be a good choice in many cases.

However, such a conclusion requires further consideration from the economic point of view, but this was not considered in this study.

\section{Conclusions}

Binary plants with dry cooling systems represent a sustainable way to exploit lowtemperature, water-dominated geothermal fields. No additional water is required and emissions of pollutants and greenhouse gases are close to zero.

However, it is clear that geothermal binary plants can be competitive with other energy conversion technologies if and only if acceptable brine consumption levels ( $\mathrm{kg} / \mathrm{s}$ per net MWe generated) can be attained. Optimal design strategies that give the best match between the geothermal resource and the power plant are required. This involves the selection of a suitable working fluid for the thermodynamic cycle and a detailed design of the plant components like the recovery heat exchanger and the cooling systems.

In this paper, a hierarchical optimization procedure for the design of binary plants has been presented and applied to a range of representative cases. A sensitivity analysis taking into account different geothermal fluid $\left(110-160^{\circ} \mathrm{C}\right)$, rejection $\left(70-100{ }^{\circ} \mathrm{C}\right)$ and condensation $(30-$ $40{ }^{\circ} \mathrm{C}$ ) temperatures, as well as various working fluids and thermodynamic cycles was presented. A study of the results permits some guidelines to be developed for the optimal matching of lower-temperature geothermal fluids and binary power plants, i.e.:

- $\quad$ Brine specific consumption to produce electrical power is mainly influenced by the difference between the source and rejection temperatures $\left(T_{\text {geo }}-T_{\text {rej }}\right)$. For the range of source temperatures analyzed $\left(110-160^{\circ} \mathrm{C}\right)$ it can vary from 20 to $120 \mathrm{~kg} / \mathrm{s}$ per MW net. It is between 20 and $24 \mathrm{~kg} / \mathrm{s}$ per MW net when the operating conditions are favorable (160-70-30) and increases to 40-50 kg/s per MWe for a lower temperature source and a higher temperature condenser (130-70-40). If the temperature difference $\left(\mathrm{T}_{\text {geo }}-\mathrm{T}_{\text {rej }}\right)$ is further reduced (e.g. 130-100; 110-80), it may not be practical to generate power. In all cases the optimal matching of organic fluids, recovery cycle and condensation temperature is of fundamental importance; 
- $\quad$ The values of First and Second Law efficiencies calculated for the basic Rankine cycle, as well as the values of brine specific consumption, are similar to those found in the literature; their variation is due primarily to differences between source and rejection temperatures. In particular, First Law efficiencies between 6\% (110-80-40) and 12\% (16070-30) can be obtained, while Second Law efficiencies are between 22\% (110-80-40) and $45 \%$ (160-70-30). Optimization of the energy conversion cycle can produce a reduction in brine specific consumption of up to $30 \%$.

- $\quad$ For each combination of geothermal fluid temperature and working fluids, there is a particular recovery cycle that permits maximization of the thermodynamic performance of the system. The important point is that the optimal design for each working fluid leads to a similar performance if one finds the best match between the working fluid, the recovery cycle and the geothermal brine. The best results are obtained with R152a and Isobutane, while there are no apparent advantages in the use of multicomponent fluids for the range of conditions studied.

- $\quad$ Particular attention must be paid to the condensation temperature. While a reduction in ambient temperature is beneficial, the optimal condenser temperature is not necessarily the lowest one. There is a range of 10 to $20^{\circ} \mathrm{C}$ above the average ambient temperature over which no beneficial effects are obtained by reducing the condensation temperature. This is because the higher thermodynamic performance of the recovery cycle is negated by the increase in fan power requirements.

- $\quad$ In some cases the advantages related to the use of complex technical solutions (e.g. supercritical, dual pressure level cycles or recuperative cycles) may be important (5-10\% in terms of a decrease in brine specific consumption), but not always. In particular the advantages are greater if a higher geothermal fluid inlet temperature $\left(140-160^{\circ} \mathrm{C}\right)$ can be used, while they are negligible if only relatively low inlet temperatures $\left(120-130{ }^{\circ} \mathrm{C}\right)$ are available. However, the real problem of the advanced recovery cycles is their high sensitivity to variations in operating conditions (e.g. a decrease in geothermal fluid inlet temperature during the lifecycle of the plant).

In conclusion, binary cycle technologies are promising because they permit the utilization of geothermal resources that could not otherwise be used to generate electricity economically. To exploit low- and medium-temperature geothermal sources on a wider scale, it is crucial to use advanced design methods and apply optimization techniques for fine-tuning plant design 
variables. This is because the results obtained are very sensitive, from both energetic and economic points of view, as well as to variations in design parameters.

Finally, it must be emphasized that binary plant technology cannot be considered in isolation from the geological aspects (depth of the reservoir, chemical composition of the geothermal fluid, sustainability of brine production). For the utilization of any geothermal resource a multidisciplinary research approach is of fundamental importance. 


\section{References}

Angelino, G., Bini, R., Bombarda, P., Gaia, M., Girardi, P., Lucchi, P., Macchi, E., Rognoni, M., Sabatelli F., 1995. 1 MW binary cycle turbogenerator model made in Europe. In: Proceedings of the 1995 World Geothermal Congress, 18-31 May, Florence, Italy, pp. 2125-2130.

Angelino, G., Colonna Di Paliano, P., 1998. Multicomponent working fluids for organic Rankine cycles (ORCs). Energy 23, 449-463.

Barbier, E., 2002. Geothermal energy technology and current status: an overview. Renewable and Sustainable Energy Reviews 6, 3-65.

Bertani, R., 2005. World Geothermal power generation in the period 2001-2005. Geothermics 34, 651-690.

Bertani, R., 2007. World Geothermal generation in 2007, Geo-Heat Center Quarterly Bulletin 28(3), 8-19.

Bertani, R., 2008. Geothermal power plants commissioned in the third millennium. IGA News 72, 5-10.

Borsukiewicz-Gozdur, A., Nowak, W., 2007. Comparative analysis of natural and synthetic refrigerants in application to low temperature Clausius-Rankine cycle. Energy 32, 344 352.

DiPippo, R., 1999. Small geothermal power plants: design, performance and economics, GeoHeat Center Quarterly Bulletin 20 (2), 1-9.

DiPippo, R., 2004. Second Law assessment of binary plants generating power from lowtemperature geothermal fluids. Geothermics 33, 565-586.

DiPippo, R., 2008. Geothermal power plants: Principles, applications, case studies and environmental impact; $2^{\text {nd }}$ edition. Butterworth-Heinemann, New York, NY, USA, 493 pp.

Franco, A., Villani, M., 2008a. Ottimizzazione di apparati di scambio termico per impianti geotermici a ciclo binario. In: Atti del XXVI Congresso Nazionale sulla Trasmissione del Calore, 23-25 June, Palermo, Italy, vol. CD.

Franco, A., Villani, M., 2008b. Optimization of binary plants for low emission power production in water dominant geothermal fields. In: Proceedings of the $6^{\text {th }}$ Biennal 
International Workshop Advances in energy studies, Towards a holistic approach based on science and humanity, 30 June-2 July, Graz, Austria, vol. CD.

Gallup, D., 1998. Aluminum silicate scale formation and inhibition: scale solubilities and laboratory and field inhibition tests. Geothermics 27, 485-501.

Gawlik, K., Kutscher, C., 2000. Investigation of the opportunity for small-scale geothermal power plants in the western United States. Geothermal Resources Council Trans. 24, 109-112.

Gnutek, Z., Bryszewska-Mazurek, A., 2001. The thermodynamic analysis of multicycle ORC engine. Energy 26, 1075-1082.

Grassiani, M., 2000. Siliceous scaling aspects of geothermal power generation using binary cycle heat recovery. In: Proceedings of the 2000 World Geothermal Congress, 28 May10 June, Kyushu-Tohoku, Japan, pp. 3167-3171.

Gu, Z., Sato, H., 2001. Optimization of cyclic parameters of a supercritical cycle for geothermal power generation. Energy Conversion and Management 42, 1409-1416.

Hettiarachchi, H.D.M., Golubovic, M., Worek, W.M., Ikegami, Y., 2007. Optimum design criteria for an Organic Rankine Cycle using low-temperature geothermal heat sources. Energy 32 1698-1706.

Hochstein, M.P., 1990. Classification and assessment of geothermal resources. In: Dickson, M.H., Fanelli, M., Small Geothermal Resources: A Guide to Development and Utilization. Unitar, New York, NY, USA, pp. 31-57.

Kanoglu, M., 2002. Exergy analysis of a dual-level binary geothermal power plant. Geothermics 31,709-724.

Kaplan, U., 2007. Organic Rankine cycles configuration. In: Proceedings of the European Geothermal Congress 2007, 30 May-1 June, Unterhaching, Germany, 5 pp.

Kose, R., 2007. Geothermal energy potential for power generation in Turkey: A case study in Simav, Kutahya. Renewable and Sustainable Energy Reviews 11, 497-511.

Liu, B., Chien, K., Wang, C., 2004. Effect of working fluids on organic Rankine cycle for waste heat recovery. Energy 29, 1207-1217.

Lund, J.W., 2007. Characteristics, development and utilization of geothermal resources. GeoHeat Center Quarterly Bulletin 28 (2), 1-9. 
Lund, J.W., Boyd, T., 1999. Small geothermal power projects examples. Geo-Heat Center Quarterly Bulletin 20 (2), 9-26.

Moya, P., DiPippo, R., 2007. Unit 5 bottoming binary plant at Miravalles geothermal field, Costa Rica: Planning, design, performance and impact. Geothermics 36, 63-96.

Mroczek, E. K., White, S.P., Graham, D.J., 2000. Deposition of amorphous silica in porous packed beds - predicting the lifetime of the reinjection aquifers. Geothermics 29, 737757.

Rao, S.S., 1996. Engineering Optimization, Theory and Practice, $3^{\text {rd }}$ Edition. John Wiley and Sons, New York, NY, USA, 920 pp.

Schochet, D.N., 1997. Performance of ORMAT geothermal binary and combined steam/binary cycle power plants with moderate and high temperature resources. Renewable Energy 10, 379-387.

Schochet, D.N., 2000. Case histories of small scale geothermal power plants, Proceedings of the 2000 World Geothermal Congress, 28 May-10 June, Kyushu - Tohoku, Japan, pp. 2201-2204.

Sones, R., Krieger Z., 2000. Case history of the binary power plant development at the Heber, California Geothermal Resource. In: Proceedings of the 2000 World Geothermal Congress, 28 May-10 June, Kyushu-Tohoku, Japan, pp. 2217-2219.

Stefansson, V., 1997. Geothermal Reinjection Experience. Geothermics 26, 99-139.

Villani, M., 2008. Development of advanced cycles for medium and low temperature geothermal sources. Master Thesis in Energy Engineering, University of Pisa, Pisa, Italy. 285 pp. (In Italian) http://etd.adm.unipi.it/theses/available/etd-12142007-121207/ 


\section{Tables}

Table 1. Worldwide installed geothermal power capacity (in MWe) from 1990 to 2007 (Bertani, 2007)

$\begin{array}{lccccr}\text { Country } & \mathbf{1 9 9 0} & \mathbf{1 9 9 5} & \mathbf{2 0 0 0} & \mathbf{2 0 0 5} & \mathbf{2 0 0 7} \\ \text { USA } & 2775 & 2816 & 2228 & 2564 & 2687 \\ \text { Philippines } & 891 & 1227 & 1909 & 1930 & 1968 \\ \text { Indonesia } & 145 & 310 & 590 & 797 & 992 \\ \text { Mexico } & 700 & 753 & 755 & 953 & 953 \\ \text { Italy } & 545 & 632 & 785 & 790 & 810 \\ \text { World } & \mathbf{5 8 3 2} & \mathbf{6 8 3 3} & \mathbf{7 9 7 2} & \mathbf{8 9 3 3} & \mathbf{9 7 3 2}\end{array}$

Table 2. Worldwide installed geothermal power capacity at the end of 2005 (Bertani, 2005)

\begin{tabular}{lcc}
\hline Type of plant & Installed capacity & (\%) \\
\hline Dry steam & 2545 & 28 \\
Single flash & 3294 & 37 \\
Double flash & 2293 & 26 \\
Binary/ Combined & 682 & 8 \\
Back pressure & 119 & 1 \\
TOTAL & $\mathbf{8 9 3 3}$ & $\mathbf{1 0 0}$ \\
\hline
\end{tabular}


Table 3. Operating binary plants of sizes larger than $10 \mathrm{MWe}$ (data from various open-file sources)

\begin{tabular}{|c|c|c|c|c|}
\hline Plant & Location & $\begin{array}{c}\text { Installed capacity * } \\
\text { (MWe) }\end{array}$ & Plant type & $\begin{array}{c}\text { Type of } \\
\text { cooling tower }\end{array}$ \\
\hline Miravalles 5 & Costa Rica & $(18)$ & Combined cycle (Binary) & Wet \\
\hline Leyte & Philippines & $(61)$ & Combined cycle (Binary) & Wet \\
\hline Mak-Ban & Philippines & $(15.7)$ & Combined cycle (Binary) & Wet/Dry \\
\hline Sao Miguel & Azores (Portugal) & 16 & Binary & Dry \\
\hline Pico Vermelho & Azores (Portugal) & 11.5 & Binary & Dry \\
\hline Mokai & New Zealand & (18) & Combined cycle (Binary) & Dry \\
\hline Rotokawa & New Zealand & 13.5 & Binary & Wet \\
\hline Wairakei & New Zealand & $(15)$ & Combined cycle (Binary) & Dry \\
\hline Zunil & Guatemala & 28.6 & Binary & Dry \\
\hline Olkaria III & Kenya & 12 & Binary & Dry \\
\hline Puna & Hawaii (USA) & $(30)$ & Combined cycle(Binary) & Dry \\
\hline Heber (SIGC) & California (USA) & 40 & Binary & Wet \\
\hline East Mesa & California (USA) & 89.4 & Binary (five plants) & Wet \\
\hline $\begin{array}{l}\text { Casa Diablo } \\
\text { (Mammoth) }\end{array}$ & California (USA) & 42 & Binary (three plants) & Dry \\
\hline Steamboat Spring & Nevada (USA) & 34 & Binary & Dry \\
\hline Salt Wells & Nevada (USA) & 14 & Binary & Dry \\
\hline Soda Lake & Nevada (USA) & 12 & Binary & Dry \\
\hline Stillwater & Nevada (USA) & 15.3 & Binary & Dry \\
\hline Stillwater 2 & Nevada (USA) & 48 & Binary & Dry \\
\hline Blundell & Utah (USA) & 11 & Binary & Dry \\
\hline
\end{tabular}

+ Capacities shown in parentheses correspond to bottoming plants 
Table 4. Small binary power plants using low-temperature geothermal resources or non-conventional working fluids (data from various open-file sources)

\begin{tabular}{|c|c|c|c|c|c|c|}
\hline Plant and location & $\begin{array}{l}\mathrm{T}_{\text {geo }} \\
\left({ }^{\circ} \mathrm{C}\right)\end{array}$ & Cycle & Working fluid & $\begin{array}{c}\text { Gross } \\
\text { capacity } \\
\text { (kWe) }\end{array}$ & $\begin{array}{l}\text { Specific brine } \\
\text { consumption } \\
{[(\mathbf{k g} / \mathbf{s}) / \mathbf{M W}]}\end{array}$ & Cooling tower \\
\hline Nigorikawa, Japan & 140 & Rankine & R114 & 1000 & 50 & Wet \\
\hline Otake, Japan & 130 & Rankine & Isobutane & 1000 & 14.7 & Wet/Dry \\
\hline Husavik, Iceland & 124 & Kalina & $\mathrm{NH}_{3}-\mathrm{H}_{2} \mathrm{O}$ & 1700 & 53 & Wet \\
\hline Nagqu, China & 110 & Rankine & Isopentane & 1000 & 69 & Dry \\
\hline Altheim, Austria & 106 & Rankine & $\mathrm{C}_{5} \mathrm{~F}_{12}$ & 1000 & 86 & Dry \\
\hline Wabuska, CA, USA & 104 & Rankine & Isopentane & 1750 & 34.3 & Wet \\
\hline Chena Hot Spring, AK, USA & 74 & Rankine & $\mathrm{R} 134 \mathrm{a}$ & 400 & 57.9 & Wet/Dry \\
\hline Kutahya-Simav, Turkey & 145 & $\begin{array}{c}\text { Rankine with } \\
\text { superheat }\end{array}$ & R124 & 2900 & 42 & Wet \\
\hline
\end{tabular}

$\mathrm{T}_{\text {geo }}$ : geothermal fluid temperature

Table 5. Refrigerant fluids suitable for binary cycle

\begin{tabular}{lcccc}
\hline Chemical compound & Type & Chemical formula & $\mathbf{T}_{\mathbf{c r}}\left({ }^{\circ} \mathbf{C}\right)$ & $\mathbf{p}_{\mathbf{c r}}(\mathbf{b a r})$ \\
\hline Isobutane & $\mathrm{HC}$ & $\mathrm{C}_{4} \mathrm{H}_{10}$ & 135.9 & 36.8 \\
n-Pentane & $\mathrm{HC}$ & $\mathrm{C}_{5} \mathrm{H}_{12}$ & 196.6 & 33.7 \\
R134a & $\mathrm{HFC}$ & $\mathrm{CH}_{2} \mathrm{~F}-\mathrm{CF}_{3}$ & 101.2 & 40.65 \\
$\mathrm{R} 152 \mathrm{a}$ & $\mathrm{HFC}$ & $\mathrm{CH}_{3} \mathrm{CH}-\mathrm{F}_{2}$ & 113.5 & 45.8 \\
$\mathrm{R} 401 \mathrm{~A}$ & $\mathrm{Mix}$ & $\mathrm{R} 22 / \mathrm{R} 152 \mathrm{a} / \mathrm{R} 124$ & 108.0 & 46.04 \\
R407C & $\mathrm{Mix}$ & $\mathrm{R} 32 / 125 / \mathrm{R} 134 \mathrm{a}$ & 86.7 & 46.19 \\
\hline
\end{tabular}

$\mathrm{T}_{\mathrm{cr}}$ : critical temperature; $\mathrm{p}_{\mathrm{cr}}$ : critical pressure 
Table 6. Effect of geothermal fluid and rejection temperature differences $\left(\mathbf{T}_{\text {geo }}-\underline{T}_{\text {rei }}\right)$ on computed results (Condensation temperature: $40^{\circ} \mathrm{C}$ )

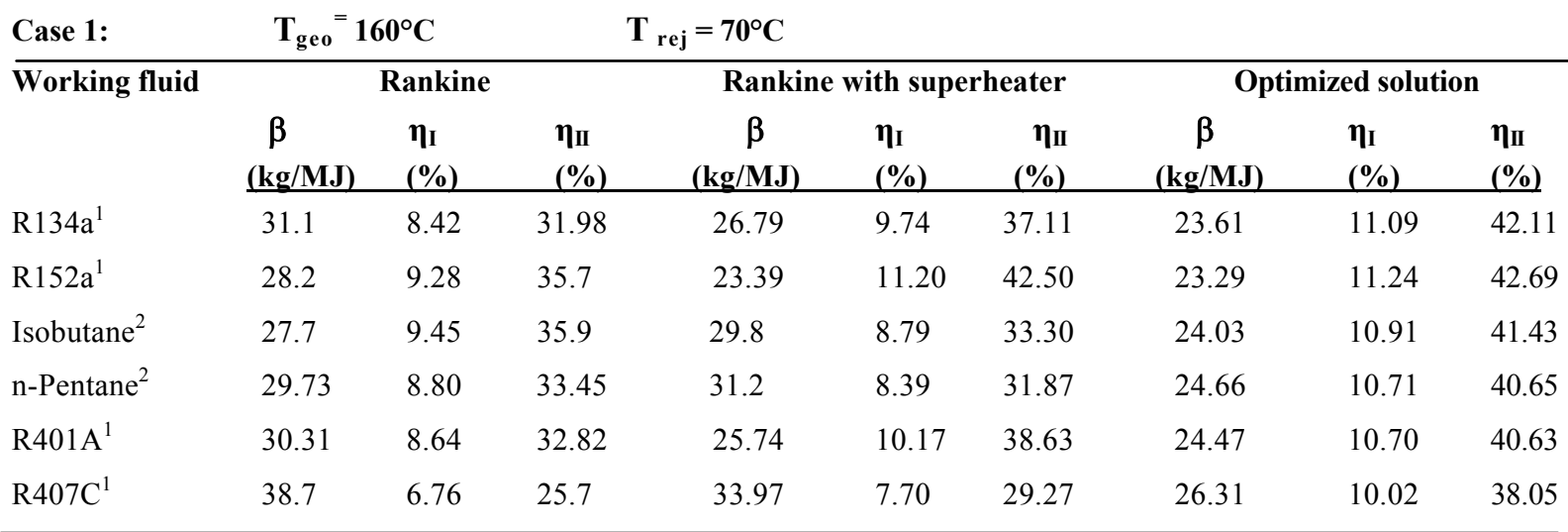

${ }^{1}$ Optimized solution: Supercritical cycle $\quad{ }^{2}$ Optimized solution: Dual pressure level Rankine cycle

Case 2: $\quad \mathrm{T}_{\text {geo }}{ }^{=} 130^{\circ} \mathrm{C} \quad \mathrm{T}_{\text {rej }}=70^{\circ} \mathrm{C}$

\begin{tabular}{|c|c|c|c|c|c|c|c|c|c|}
\hline \multirow[t]{2}{*}{ Working fluid } & \multicolumn{3}{|c|}{ Rankine } & \multicolumn{3}{|c|}{ Rankine with superheater } & \multicolumn{3}{|c|}{ Optimized solution } \\
\hline & $\begin{array}{l}\beta \\
(\mathrm{kg} / \mathrm{MJ})\end{array}$ & $\begin{array}{l}\eta_{I} \\
(\%)\end{array}$ & $\begin{array}{l}\eta_{\text {II }} \\
(\%)\end{array}$ & $\begin{array}{c}\beta \\
(\mathrm{kg} / \mathbf{M J}) \\
\end{array}$ & $\begin{array}{l}\eta_{I} \\
(\%)\end{array}$ & $\begin{array}{r}\eta_{\text {II }} \\
(\%) \\
\end{array}$ & $\begin{array}{c}\beta \\
(\mathrm{kg} / \mathrm{MJ}) \\
\end{array}$ & $\begin{array}{l}\eta_{I} \\
(\%)\end{array}$ & $\begin{array}{l}\eta_{\text {II }} \\
(\%)\end{array}$ \\
\hline $\mathrm{R} 134 \mathrm{a}^{1}$ & 50.3 & 7.84 & 31.29 & 43.99 & 8.98 & 35.77 & 43.99 & 8.98 & 35.77 \\
\hline $\mathrm{R} 152 \mathrm{a}^{2}$ & 47.48 & 8.32 & 33.14 & 52.40 & 7.53 & 30.03 & 42.68 & 9.25 & 36.87 \\
\hline Isobutane $^{2}$ & 53.1 & 7.44 & 29.63 & 56.70 & 6.95 & 27.71 & 43.90 & 9.00 & 35.84 \\
\hline $\mathrm{n}$-Pentane ${ }^{2}$ & 55.26 & 7.15 & 28.48 & 58.20 & 6.78 & 27.02 & 44.60 & 8.86 & 35.27 \\
\hline $\mathrm{R} 401 \mathrm{~A}^{1}$ & 49.43 & 7.99 & 31.84 & 51.23 & 7.70 & 30.72 & 44.18 & 8.94 & 35.62 \\
\hline $\mathrm{R} 407 \mathrm{C}^{3}$ & 53.43 & 7.40 & 27.38 & 53.43 & 7.40 & 27.38 & 49.99 & 7.91 & 31.48 \\
\hline
\end{tabular}

${ }^{1}$ Optimized solution: Rankine cycle with superheater ${ }^{2}$ Optimized solution: Dual Pressure Level Rankine cycle

${ }^{3}$ Optimized solution: Supercritical cycle

Case 3: $\quad \mathrm{T}_{\text {geo }}={ }^{=} 150^{\circ} \mathrm{C} \quad \mathrm{T}_{\text {rej }}=80^{\circ} \mathrm{C}$

\begin{tabular}{|c|c|c|c|c|c|c|c|c|c|}
\hline \multirow{2}{*}{ Working fluid } & \multicolumn{3}{|c|}{ Rankine } & \multicolumn{3}{|c|}{ Rankine with superheater } & \multicolumn{3}{|c|}{ Optimized solution } \\
\hline & $\begin{array}{c}\beta \\
(\mathrm{kg} / \mathrm{MJ}) \\
\end{array}$ & $\begin{array}{l}\eta_{I} \\
(\%) \\
\end{array}$ & $\begin{array}{l}\eta_{\text {II }} \\
(\%)\end{array}$ & $\begin{array}{c}\beta \\
(\mathrm{kg} / \mathrm{MJ}) \\
\end{array}$ & $\begin{array}{l}\eta_{I} \\
(\%) \\
\end{array}$ & $\begin{array}{r}\eta_{\text {II }} \\
(\%) \\
\end{array}$ & $\begin{array}{c}\beta \\
(\mathrm{kg} / \mathrm{MJ}) \\
\end{array}$ & $\begin{array}{l}\eta_{I} \\
(\%) \\
\end{array}$ & $\begin{array}{l}\eta_{\text {II }} \\
(\%)\end{array}$ \\
\hline $\mathrm{R} 134 \mathrm{a}^{1}$ & 43.1 & 7.81 & 26.53 & 35.09 & 9.60 & 32.60 & 30.94 & 10.89 & 36.98 \\
\hline $\mathrm{R} 152 \mathrm{a}^{1}$ & 37.72 & 8.93 & 30.33 & 31.25 & 10.78 & 36.61 & 31.04 & 10.85 & 36.86 \\
\hline Isobutane $^{2}$ & 34.07 & 9.89 & 33.57 & 36.38 & 9.27 & 31.45 & 29.36 & 11.47 & 38.97 \\
\hline n-Pentane ${ }^{2}$ & 35.19 & 9.57 & 32.51 & 37.39 & 9.00 & 30.60 & 29.75 & 11.33 & 38.46 \\
\hline $\mathrm{R} 401 \mathrm{~A}^{1}$ & 39.23 & 8.60 & 29.16 & 34.28 & 9.83 & 33.36 & 31.36 & 10.74 & 36.48 \\
\hline $\mathrm{R} 407 \mathrm{C}^{1}$ & 51.94 & 6.48 & 22.02 & 44.14 & 7.63 & 25.92 & 38.99 & 8.64 & 29.34 \\
\hline
\end{tabular}

${ }^{1}$ Optimized solution: Supercritical cycle $\quad{ }^{2}$ Optimized solution: Dual pressure level Rankine cycle 


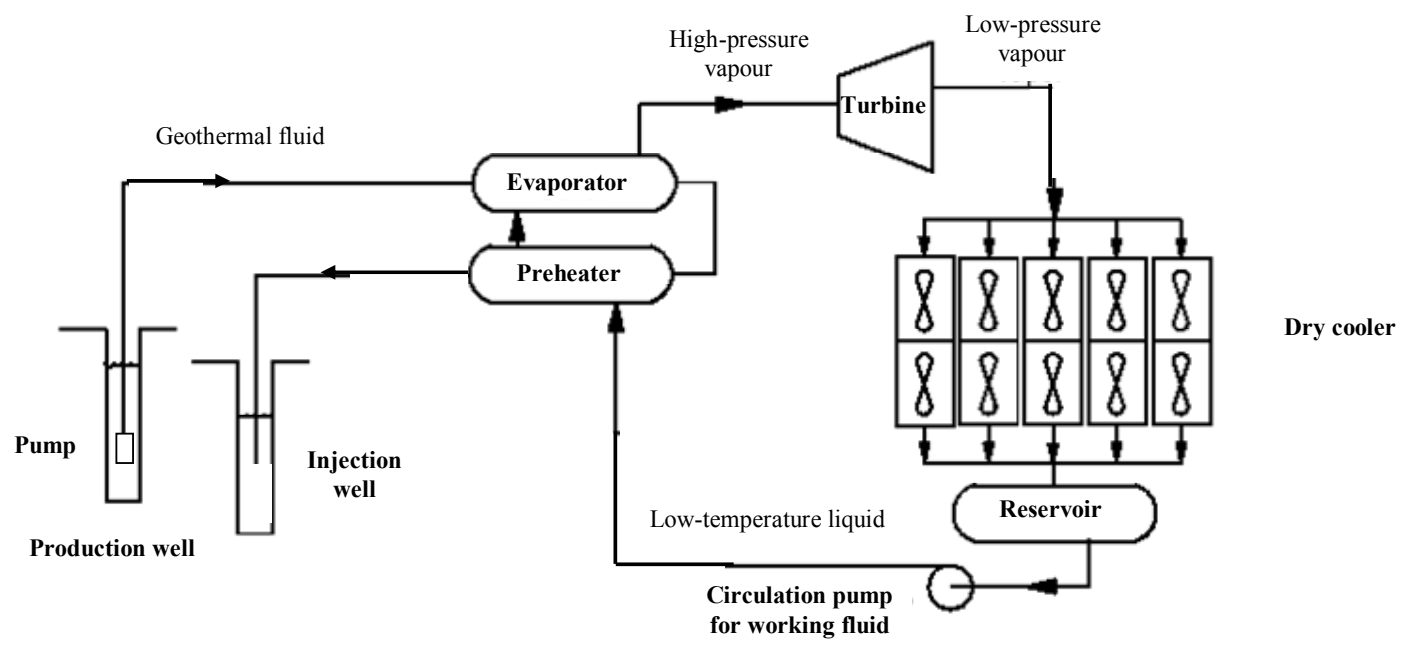

Fig. 1. Schematic diagram of a binary geothermal binary plant with a dry cooling system. 

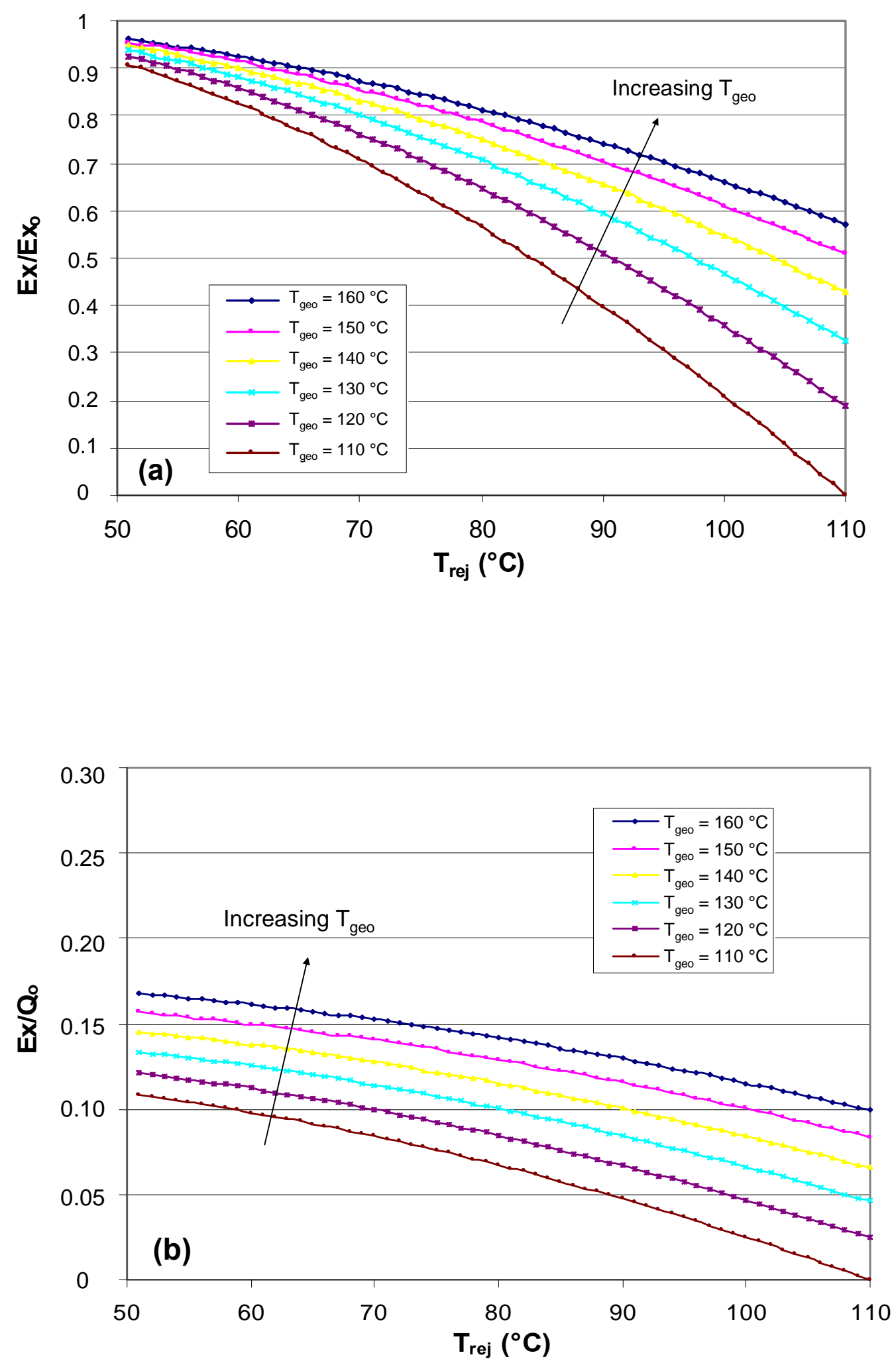

Fig. 2. Reference values for Second (a) and First (b) Law efficiencies of geothermal binary plants as a function of the available temperature difference $T_{\text {geo }}-T_{\text {rej }}$ 

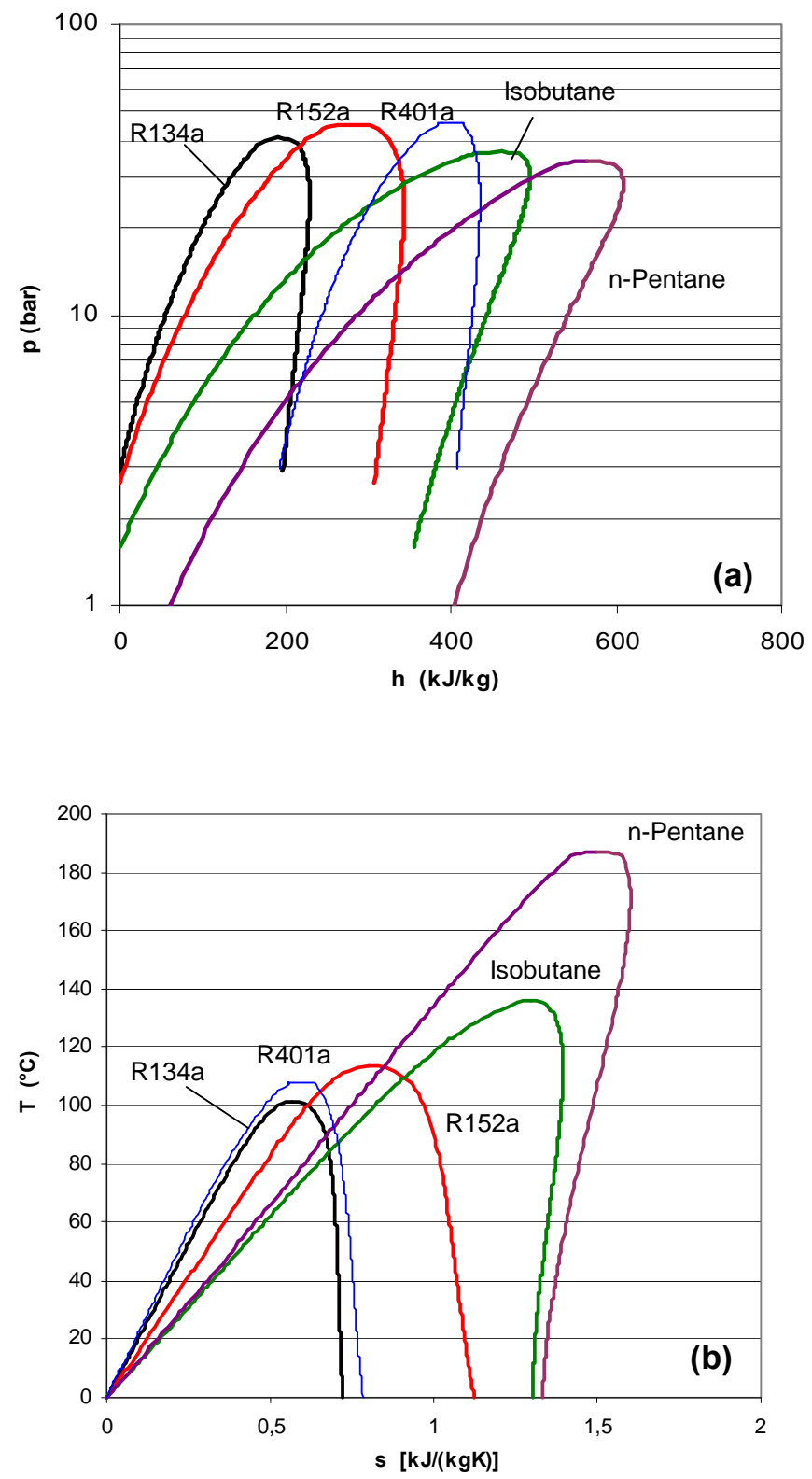

Fig. 3. Thermodynamic phase diagrams for typical working fluids used in binary plants:

(a) $\ln (\mathrm{p})$-h diagram; (b) T-s diagram. 


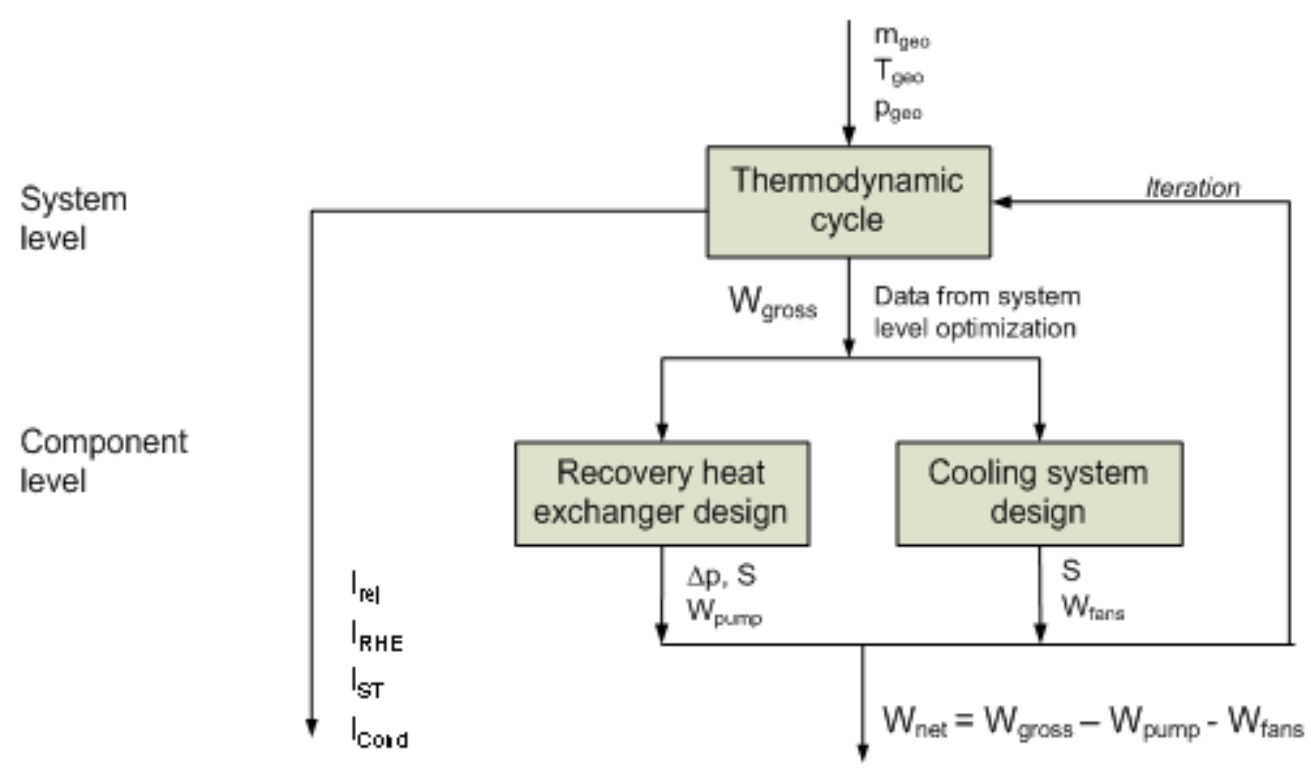

Fig. 4. Hierarchical organization for the optimal design of binary plants 


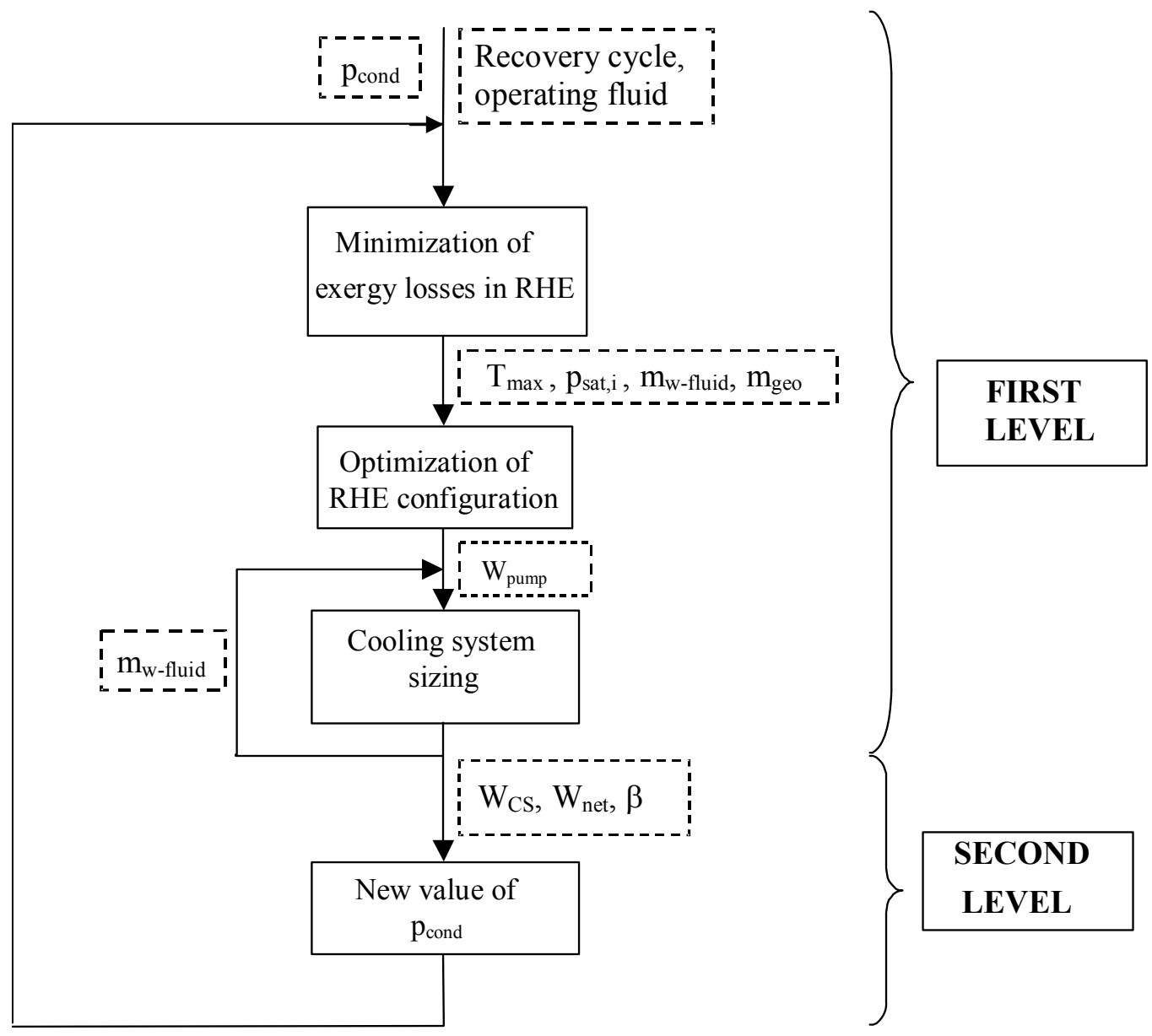

Fig. 5. More detailed definition of the optimization loop 


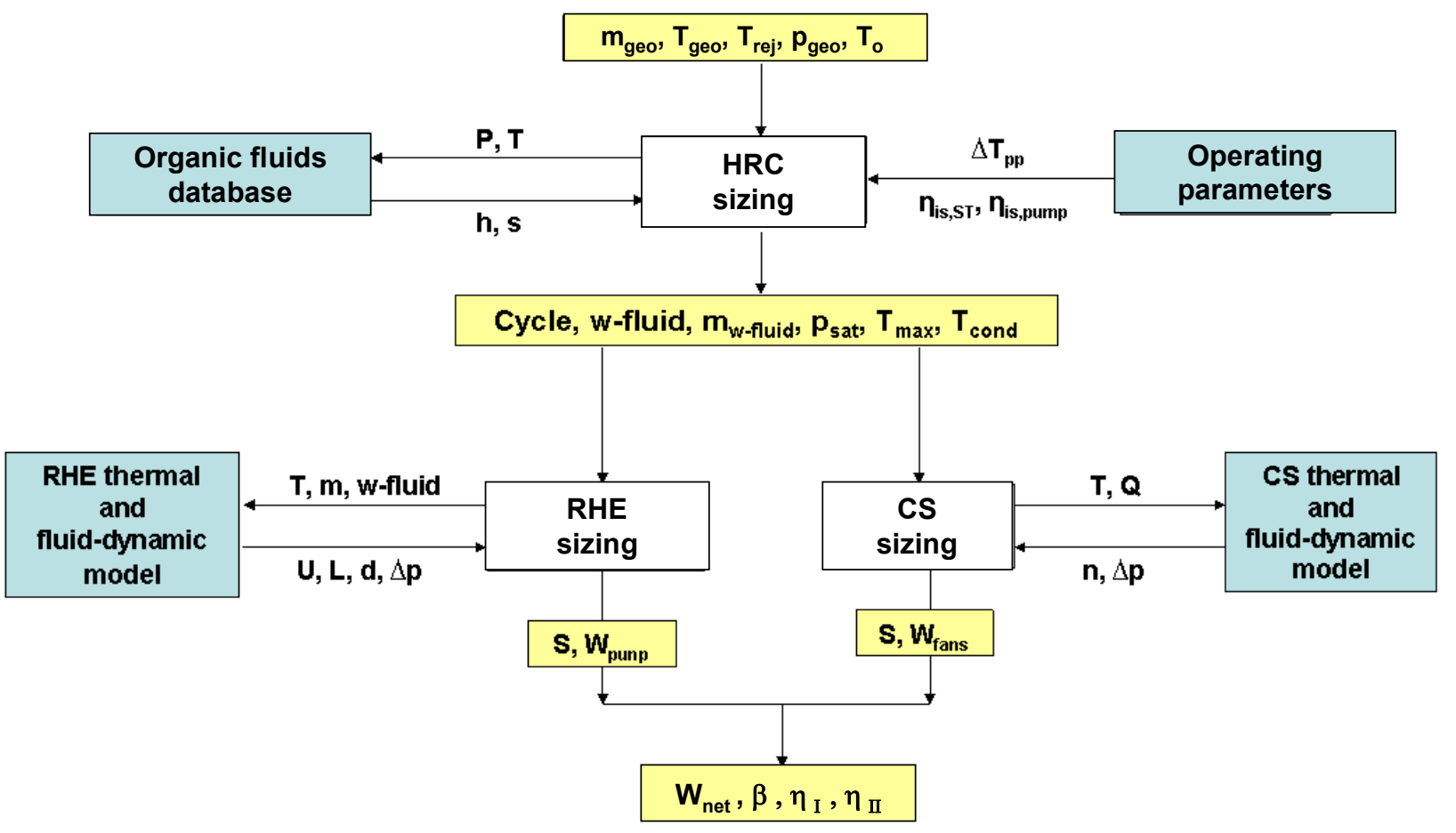

Fig. 6. Schematic diagram of the optimum design procedure. CS: Cooling system; HRC: Heat recovery cycle; RHE: Recovery heat exchanger. 

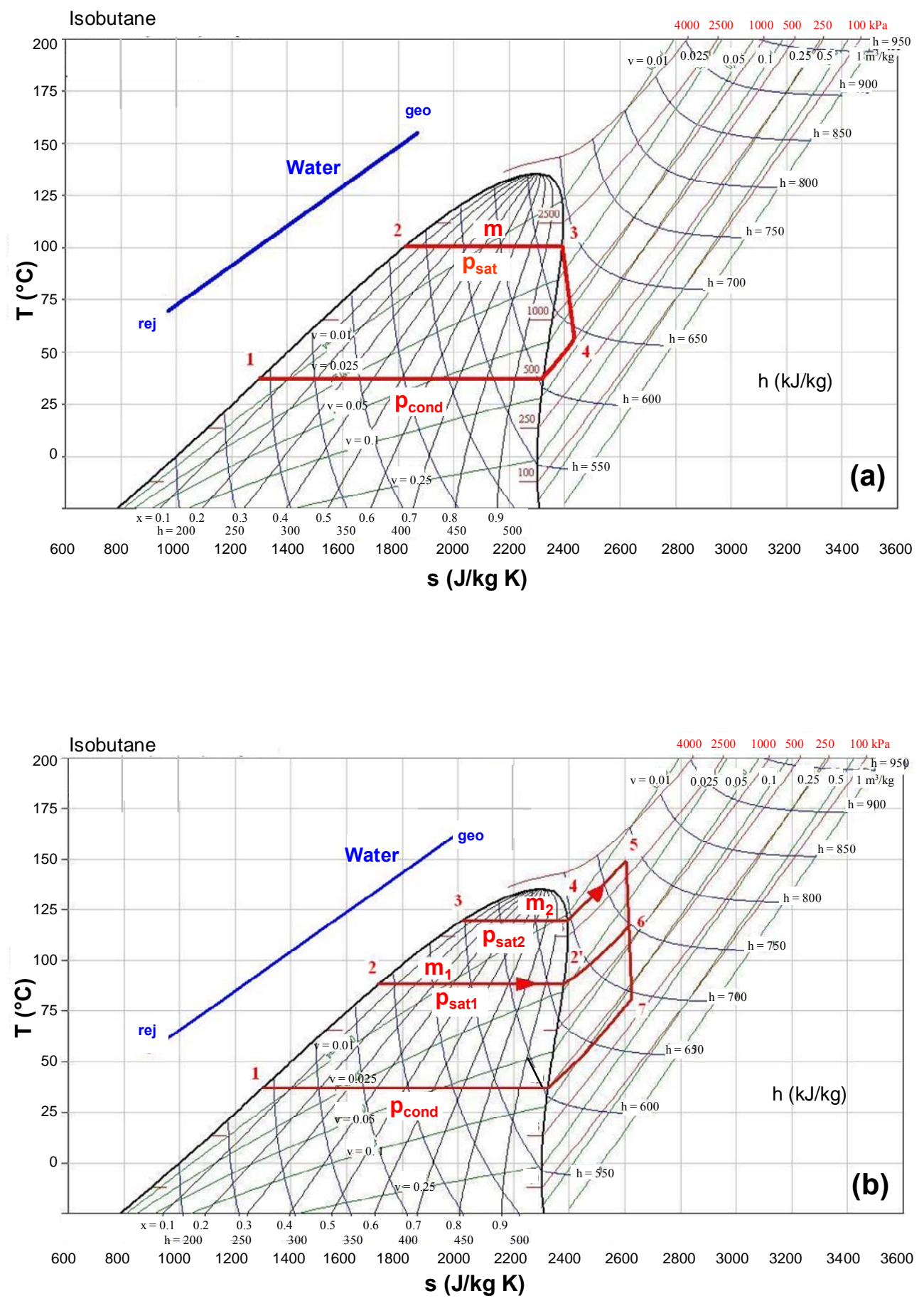

Fig. 7. Thermodynamic cycles for binary plants with Isobutane as working fluid:

(a) Rankine Cycle (RAN) and (b) Dual pressure level with superheater (DPLSH) cycle 


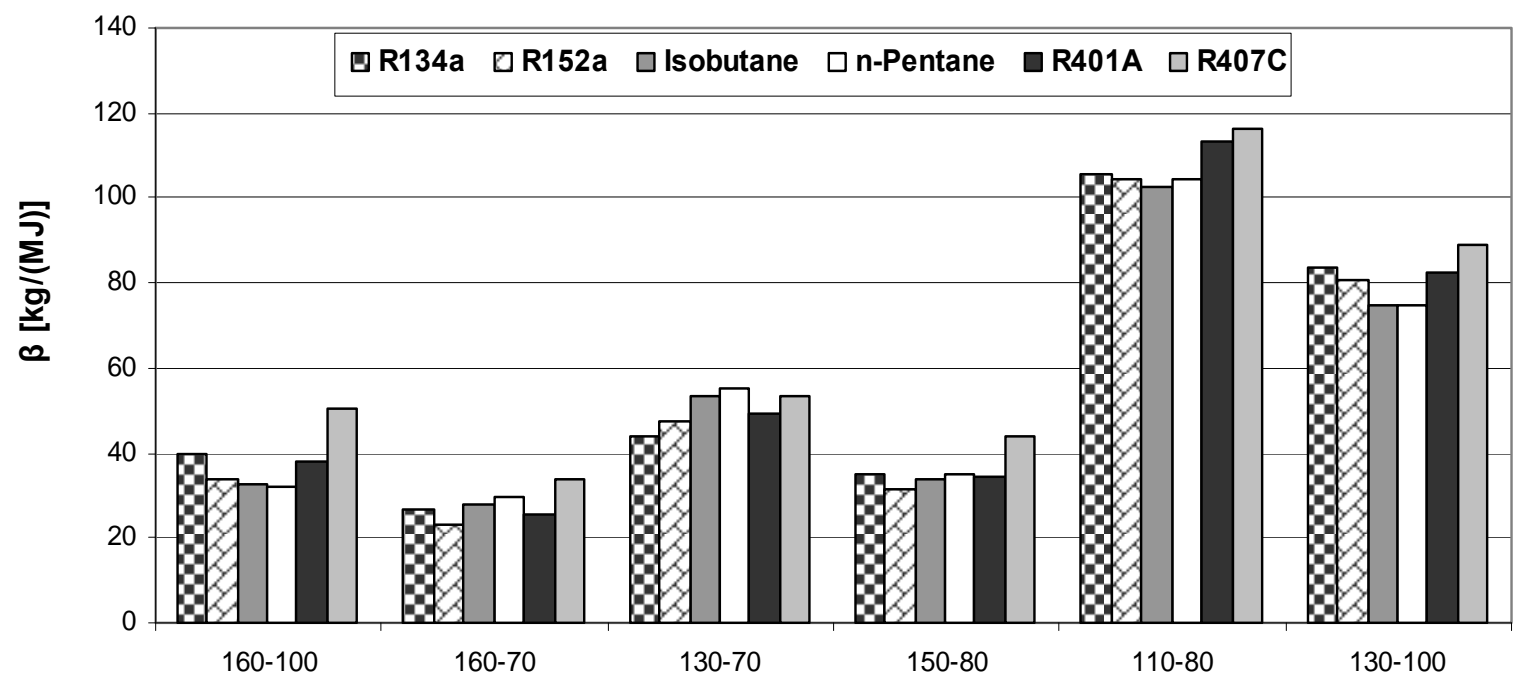

Fig. 8. Rankine and Rankine with superheat cycles. Geothermal brine specific consumption $(\beta)$ for various geothermal fluid and rejection temperatures and their differences; assumed condensation temperature: $40{ }^{\circ} \mathrm{C}$. Numbers shown below the bars correspond to $\mathrm{T}_{\text {geo }}$ and $\mathrm{T}_{\text {rej }}$ (given in ${ }^{\circ} \mathrm{C}$ ) 


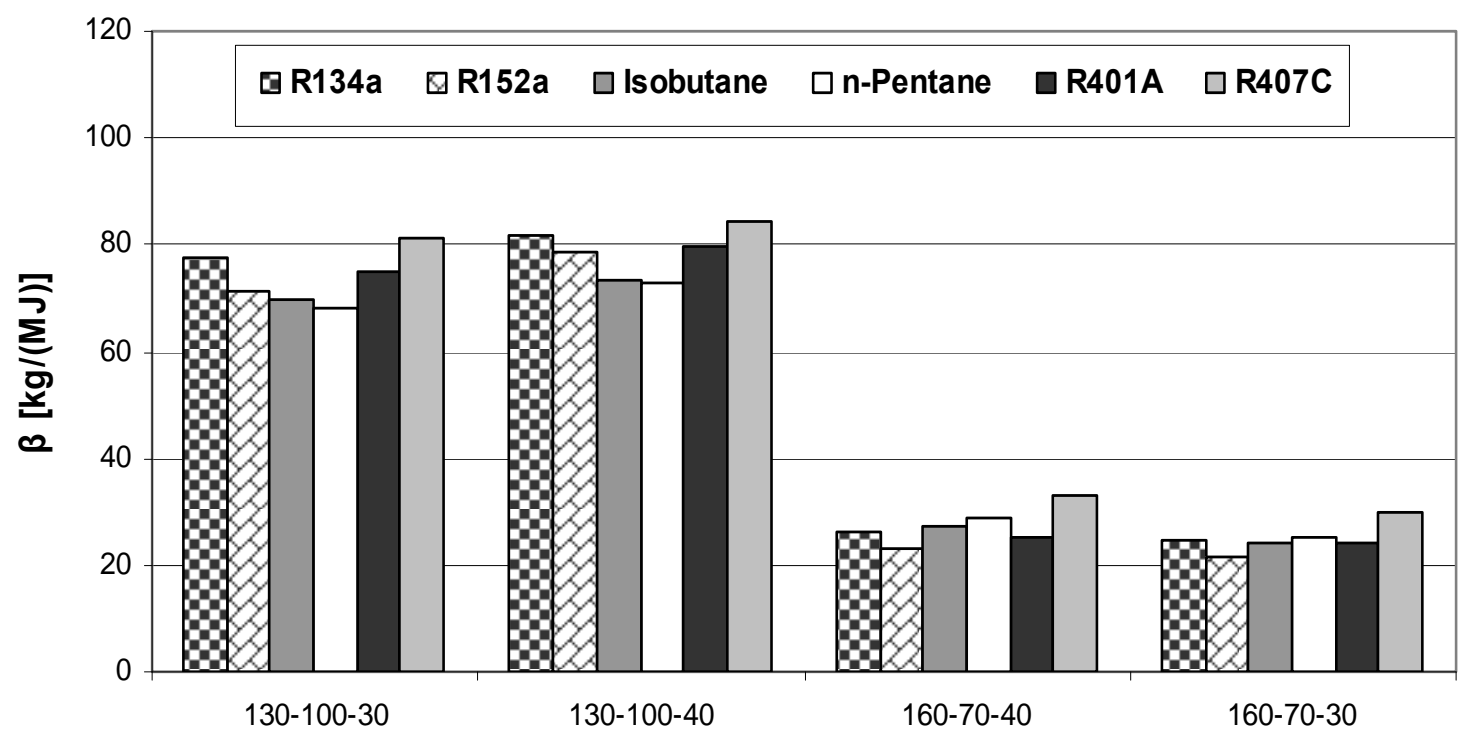

Fig. 9. Rankine and Rankine with superheat cycles. Influence of changes in condensing temperature on geothermal brine specific consumption. Numbers shown below the bars correspond to $\mathrm{T}_{\text {geo }}, \mathrm{T}_{\text {rej }}$ and $\mathrm{T}_{\text {cond }}\left(\right.$ given in ${ }^{\circ} \mathrm{C}$ ) 


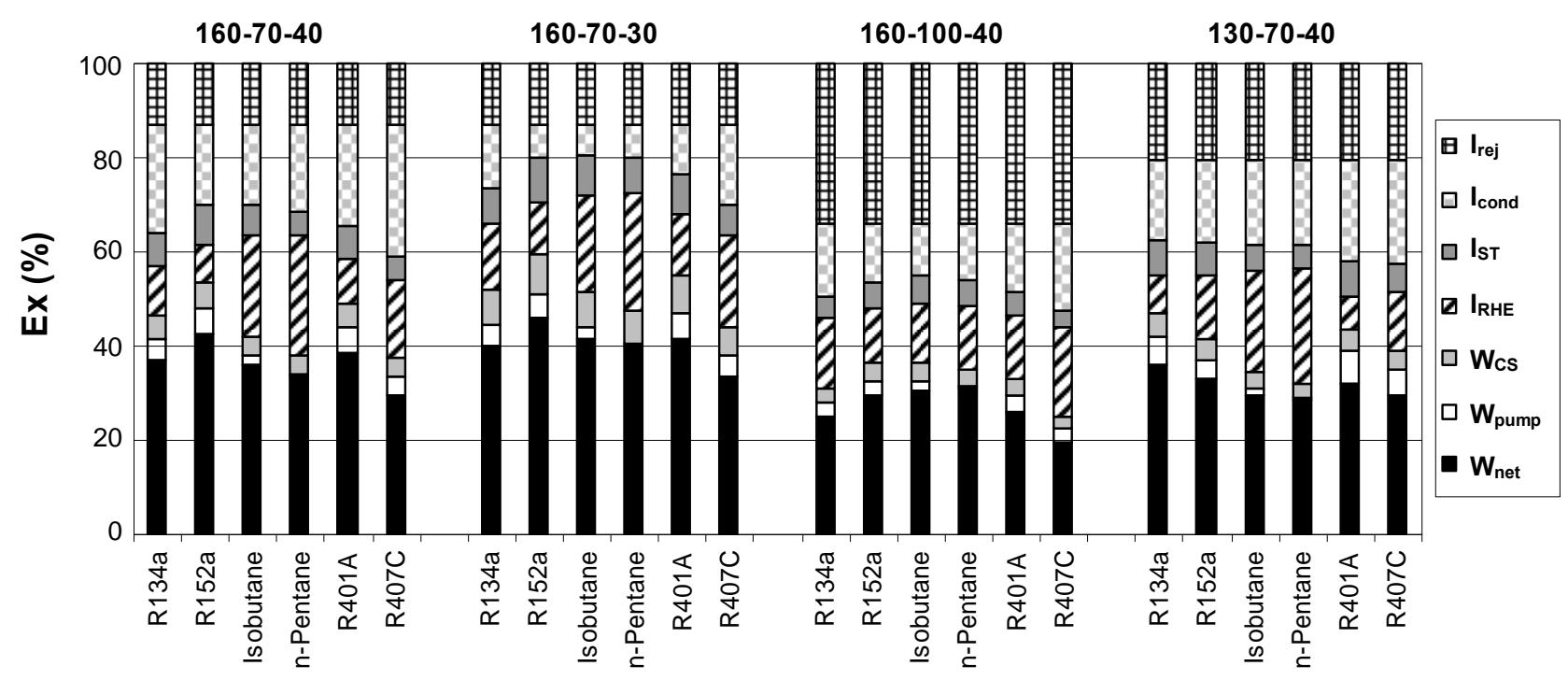

Fig. 10. Exergetic analysis for an optimal binary cycle power plant considering some representative temperatures. Numbers shown above the bars correspond to $\mathrm{T}_{\text {geo }}, \mathrm{T}_{\text {rej }}$ and $\mathrm{T}_{\text {cond }}\left(\right.$ given in ${ }^{\circ} \mathrm{C}$ ) 


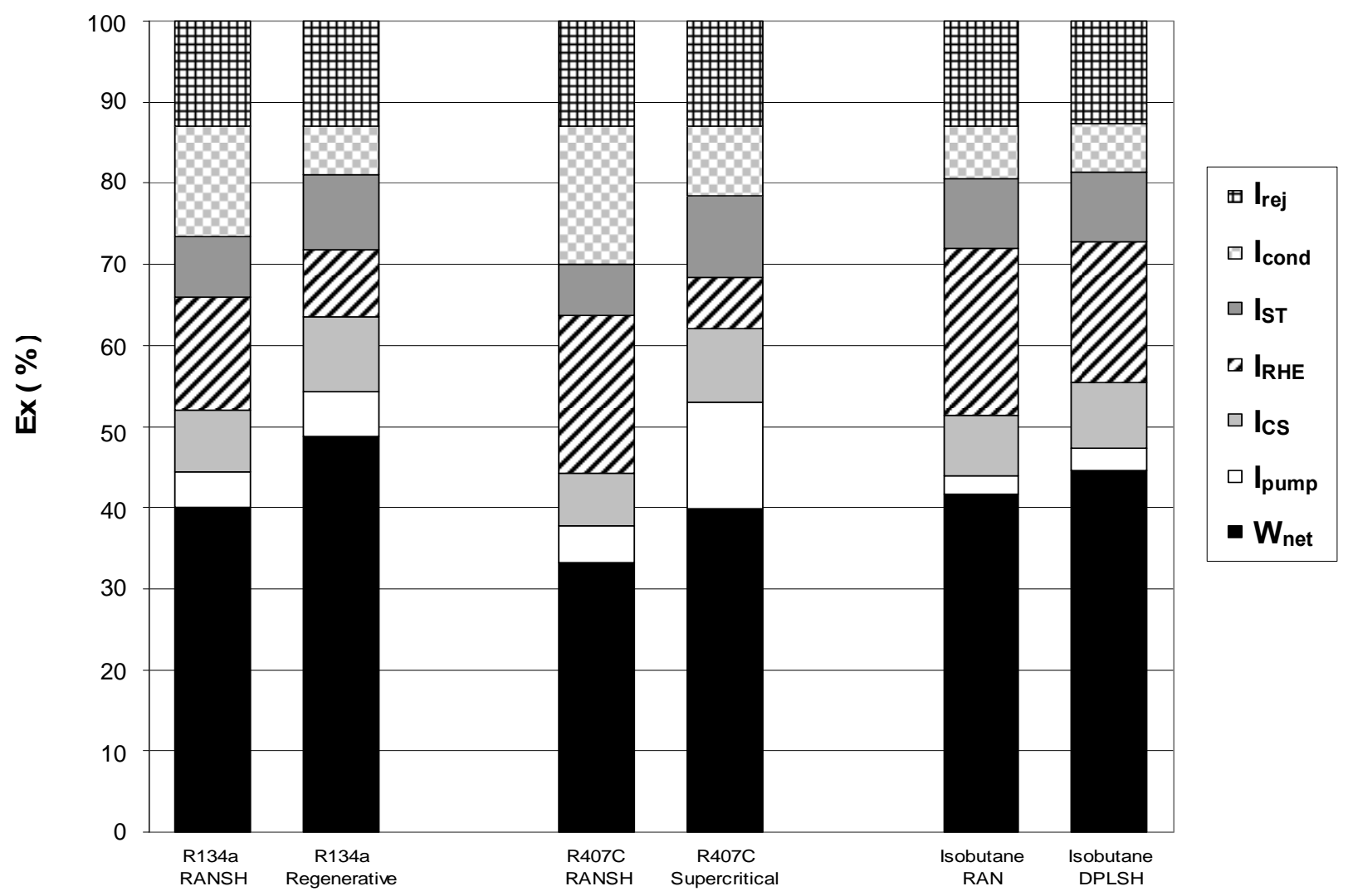

Fig. 11. Performance improvement of the binary cycle due to the use of advanced recovery cycles. These results correspond to $\mathrm{T}_{\text {geo }}=160^{\circ} \mathrm{C}, \mathrm{T}_{\text {rej }}=70^{\circ} \mathrm{C}$ and $\mathrm{T}_{\text {cond }}=30^{\circ} \mathrm{C}$ (i.e. case 160-70-30). RANSH denotes Rankine cycle with superheat. 